ADRIANA BARBOSA GONÇALVES

ESTUDO CITOGENÉTICO, REGIÕES 2q37 E 22q13.3 E CONDIÇÕES MÉDICAS EM DOENÇAS DO ESPECTRO AUTÍSTICO 


\title{
Estudo Citogenético, Regiões 2q37 e 22q13.3 e Condições Médicas em Doenças do Espectro Autístico
}

Tese apresentada para obtenção do título de Doutor em Genética junto ao Programa de Pós-Graduação em Genética do Instituto de Biociências, Letras e Ciências Exatas da “, Câmpus de São José do Rio Preto.

\section{BANCA EXAMINADORA}

\author{
Profa. Dra. Agnes C. Fett Conte \\ Professor Adjunto Livre-Docente \\ FAMERP - São José do Rio Preto \\ Orientadora
}

Profa. Dra. Andréa Borduchi Franco Salles Professor Adjunto UNIP - São José do Rio Preto

Profa. Dra. Flávia Lisoni Professor Adjunto UNESP - Ilha Solteira

Prof. Dr. João Monteiro de Pina Neto Professor Adjunto Livre-Docente USP - Ribeirão Preto

Prof. Dr. Luiz Carlos de Matos Professor Adjunto Livre-Docente FAMERP - São José do Rio Preto 
Barbosa-Gonçalves, Adriana.

Estudo Citogenético, Regiões 2q37 e 22q13.3 e Condições Médicas em Pacientes com Doenças do Espectro Autista / Adriana BarbosaGonçalves. - São José do Rio Preto : [s.n.], 2010. 92 f. : il. ; $30 \mathrm{~cm}$.

Orientador: Agnes Cristina Fett Conte

Tese (Doutorado) - Universidade Estadual Paulista, Instituto de Biociências, Letras e Ciências Exatas.

1. Autismo. 2. Doenças do Espectro Autístico. 3. Comorbidade. 4. 2q37. 5. 22q13.3 I. Fett-Conte, Agnes Cristina. II. Universidade Estadual Paulista, Instituto de Biociências, Letras e Ciências Exatas. III. Título. 
Este trabalho foi desenvolvido no Laboratório de Genética, junto ao Departamento de Biologia Molecular da Faculdade de Medicina de São José do Rio Preto - FAMERP com Bolsa Auxílio à Pesquisa (BAP) 2007/2009, e no Instituto de Biociências, Letras e Ciências Exatas de São José do Rio Preto (UNESP/IBILCE), com auxílio financeiro do CNPq (Processo no. 141282/2007-0 ). 
Dedico este trabalho,

À minha filha Maria Fernanda Barbosa Gonçalves, razão do meu viver. Desde a sua concepção foram muitas as batalhas....., ultrapassamos todas. Obrigada pelos gritinhos, sorrisos, carinho e por me fazer entender o real significado da palavra Mãe.

Ao esposo, Fausto da Silva Gonçalves por todo seu amor, carinho, dedicação, companheirismo e principalmente paciência. 
Aos meus pais, Wilson Barbosa de Oliveira e Adélia Gambim Oliveira, que por uma vida de dedicação, amor e trabalho sempre possibilitaram a suas filhas a oportunidade de realizar sonhos e conquistas.

Às minhas irmãs Andressa Barbosa de Oliveira e Vanessa Barbosa de Oliveira, por toda a ajuda, carinho e incentivo. Vocês são maravilhosas, não tenho palavras para agradecer toda a ajuda. Obrigada. 
Considero que a elaboração de uma tese de doutorado é um produto coletivo embora sua redação, responsabilidade e stress seja predominantemente individual.

Gostei de aprender que existem pessoas que se identificam, ou não, que a pesquisa é difícil, mas surpreendente; mas com certeza o que eu mais gostei foi aprender que o esforço vale a pena! Sim, hoje eu sei!

Hoje eu sei que o mais importante é a aprendizagem. Aprender o que ainda não sei. Ah! E como existem coisas a serem aprendidas! E por isso serei sempre uma aprendiz.

Eu creio que esta parte de agradecimentos é uma tarefa difícil, pois muitas vezes cometemos injustiças e por esquecimento não mencionamos nomes de pessoas que também contribuíram para o trabalho.

$\mathrm{Na}$ vida não conquistamos nada sozinhos. Sempre precisamos de outras pessoas para alcançar os nossos objetivos. Muitas vezes um simples gesto pode mudar a nossa vida e contribuir para o nosso sucesso.

Este trabalho só foi possível com a colaboração de várias pessoas, as quais gostaria de agradecer imensamente. A todas elas registro minha gratidão:

À Deus, que, por meio da fé, me dá forças para lutar, ilumina meu caminho, mostra-me o verdadeiro sentido da vida e me faz acreditar que nada é impossível quando a causa é justa e a vontade verdadeira. Agradeço por confortar o meu coração nas horas mais difíceis, pela coragem e objetivos alcançados.

A todos os pacientes e suas famílias, pela disponibilidade de tempo para nos atender, pelas informações fornecidas e pelo carinho. Vocês são parte fundamental deste trabalho e também minha maior recompensa.

À Prof ${ }^{a}$. Dr ${ }^{a}$. Agnes Cristtina Fett Conte, orientadora deste trabalho. Fonte de inspiração. Meu muito obrigado pela amizade, carinho, dedicação, paciência e orientação ao longo de todos estes anos. Você é uma amiga mais que especial; é responsável por eu ser uma mulher e profissional melhor.

À amiga e companheira Ana Luiza Bossolani Martins pela confiança e companheirismo em todas as coletas, finais de semana de trabalho e todo o período da minha gravidez. Você foi fundamental para a realização deste trabalho. Muito obrigada. 
À amiga Carina Tatiana Giunco responsável por eu ter me apaixonado pelas Doenças do Espectro Autístico. Nós sabemos o verdadeiro significado da palavra amizade.

À amiga Paula Maria Abdala Buassi pelas conversas e por toda experiência transmitida.

À Dra Cristina Benitez Vendrame Goloni, colaboradora deste trabalho. Obrigada por toda a ajuda técnica e por disponibilizar seu tempo tão precioso.

Às amigas do Laboratório de Genética Brasilina de Fátima Mafei, Valéria Cristina Ferrarese da Silva, Andréa Borduchi e ao amigo Fábio Sanches, do Laboratório de Biologia Molecular do Hemocentro de S. J. Rio Preto, por sempre estarem dispostos a nos ajudar.

Às pós-graduandas Camila Ive e Paula Curi pelo respeito e por toda a ajuda disponibilizada.

À Diretoria e todos os funcionários da Associação dos Amigos dos Autistas (AMA) de Ribeirão Preto, pelo respeito e imenso carinho recebidos nas inúmeras visitas e solicitações.

À Diretoria e funcionários do Recanto Tia Marlene de Votuporanga, por confiar no nosso trabalho, nos colocar em contato com as famílias e disponibilizar todos os dados solicitados.

À Diretoria e todos os funcionários da Escola Municipal do Autista "Maria Lúcia de Oliveira (EMA) de São José do Rio Preto, pelo apoio recebido durante a realização deste trabalho.

À Dra Simone Secco da Rocha, psiquiatra, colaboradora deste trabalho, pela realização dos diagnósticos dos pacientes.

Ao Dr. Antonio Richieri Costa, geneticista e neurologista, por nos auxiliar nos diagnósticos das condições médicas associadas às Doenças do Espectro Autístico.

Ao Prof. Dr, Octávio Ricci Junior, Diretor do Hemocentro, pela autorização de uso das dependências onde os procedimentos técnicos foram realizados.

Ao Prof. Dr. Luiz Carlos de Mattos, do Laboratório de Imunogenética Hemocentro/FAMERP, por ceder o laboratório para a realização da quantificação das amostras de DNA deste estudo.

À Profa Dra Cláudia Regina Bonini, do Laboratório de Hemoglobinas IBILCE/UNESP de S. J. do Rio Preto, por nos emprestar o termociclador para a 
realização da PCR nas amostras dos indivíduos sugestivos da Síndrome do Cromossomo X Frágil.

À Profa Dra Angela M. Vianna Morgante, do Departamento de Biologia IB/USP-SP, pela realização do Southern Blotting nas amostras dos indivíduos sugestivos da Síndrome do Cromossomo X Frágil.

A todos os professores e funcionário do Programa de Pós-Graduação em Genética do Instituto de Biociências, Letras e Ciências Exatas (IBILCE/UNESP) de S. J. do Rio Preto, pela atenção e dedicação.

À Diretoria do Instituto de Biociências, Letras e Ciências Exatas (IBILCE/UNESP) de S. J. do Rio Preto, pela oportunidade e concessão das condições necessárias para o desenvolvimento dos projetos científicos vinculados ao Curso de Pós-Graduação.

Ao Sr David Hewitt pela tradução para a língua inglesa de todos os artigos confeccionados e pela tradução do abstract.

Aos membros da banca examinadora, pela disponibilidade e atenção.

Ao CNPq, pela concessão de bolsa de doutorado por 3 anos.

À Faculdade de Medicina de Rio Preto (FAMERP) pela concessão de Bolsa Auxílio à Pesquisa (BAP) por 2 anos.

A todos aqueles que torceram por mim e que no cotidiano da vida me ajudam a “crescer”. Há muito mais a quem agradecer... A todos aqueles que, embora não nomeados, por suas presenças afetivas inesquecíveis, o meu reconhecido e carinhoso muito obrigado!

Todos vocês são co-autores deste trabalho 
"Eu conheço crianças que brincam diferente.

Crianças que não falam e não respondem às minhas perguntas da mesma forma que as outras de sua idade...

Crianças que pouco me olham, mas que me observam muito...

Crianças que me ensinam diariamente uma maneira diferente de brincar, pois para essas crianças aqueles meus brinquedos tradicionais pouco significam...

Crianças das quais temos muito o que descobrir são essas crianças que me encantam!"

(Autor desconhecido) 
“Só sei que nada sei”.

(Sócrates) 
As Doenças do Espectro Autístico (DEA) são afecções do neurodesenvolvimento que ocorrem em um contínuo de gravidade e comprometem a interação social, a comunicação e o comportamento dos afetados. A prevalência é muito alta na população e o esclarecimento das causas, ainda desconhecidas na maioria dos casos, tem implicações na prática clínica. A complexidade etiológica tem fomentado muitas investigações, que têm revelado loci de susceptibilidade, alterações cromossômicas e associação com outras condições médicas, além da ação de componentes ambientais. Entre as alterações genéticas propostas estão as deleções em 2q37 e 22q13.3. Este trabalho teve como objetivos a investigação genético-clínica, cariótipica por bandamento GTG, das regiões subteloméricas 2q37 e 22q13.3 por Hibridização in situ Fluorescente (FISH), com as sondas D2S447 e N85A3, e de mutação no gene $F M R 1$ por técnicas moleculares, em 71 indivíduos com estas doenças. Entre eles, oito (11.3\%) apresentaram outras condições médicas associadas, de etiologia cromossômica em um (1.4\%) (Síndrome do 5q-), gênica em três (4.22\%) (Síndrome do Cromossomo X Frágil, Síndrome de Sotos e Sindrome de Van der Woude) e ambiental em quatro (5.63\%) [Síndrome da Rubéola Fetal, Síndrome do Álcool Fetal (dois casos) e Anóxia Neonatal]. Nenhum indivíduo apresentou alterações em 2q37 e em 22q13.3. Trata-se da primeira descrição da associação entre Síndrome do 5q- e Sindrome de Van der Woude com DEA. Os resultados mostram a importância do screening destes indivíduos quanto a presença de doenças genéticas ou fatores ambientais associados, pela variedade de mecanismos biológicos envolvidos, que devem ser elucidados, e pelas implicações no prognóstico, terapêutica e no Aconselhamento Genético das famílias. A introdução da análise de regiões específicas como 2q37 e 22q13.3 no protocolo de investigação genética de rotina dos indivíduos com DEA parece não ser necessária.

Palavras-chave: Autismo; Doenças do Espectro Autístico; comorbidade, 2q37; 22q13.3. 
Autism Spectrum Disorders (ASD) are neurodevelopment disorders that vary in severity and impair the social interaction, communication and behavior of sufferers. The prevalence is very high in the population and an elucidation of the causes, which are still not well understood in most cases, has implications in the clinical practice. This etiological complexity has encouraged many investigations that have identified loci related to susceptibility, chromosomal alterations and associations with other medical conditions, as well as the action of environmental aspects. Among proposed genetic alterations are deletions in the chromosome regions $2 q 37$ and $22 q 13.3$. The aims of this study were to perform a genetic-clinical investigation of 71 individuals with ASD as well as studies using karyotyping by GTG banding, Fluorescent in situ hybridization (FISH), probes D2S447 and N85A3, of the 2q37 and 22q13.3 subtelomeric regions and of the FMR1 gene mutation using molecular techniques. Of the participating individuals, eight $(11.3 \%)$ presented with other associated medical conditions: one (1.4\%) had a chromosomal aberration (syndrome do 5q-), three (4.22\%) had associated genetic conditions (Fragile X syndrome, Soto's syndrome and Van der Woude syndrome) and four (5.63\%) had environmental-related anomalies [congenital rubella syndrome, fetal alcohol syndrome -2 cases and neonatal anoxia]. None of the individuals presented with alterations in the $2 q 37$ and $22 q 13.3$ regions. This is the first description of associations of ASD with 5q- syndrome and also ASD with Van der Woude syndrome. The results demonstrate the importance of screening in these individuals to identify the presence of associated genetic diseases or environmental factors due to the variety of biological mechanisms involved that can be elucidated and because of the implications on the prognosis, therapy and on genetic counseling of families. The introduction of the analysis of specific regions such as $2 \mathrm{q} 37$ and $22 \mathrm{q} 13.3$ in the routine genetic investigation protocol of individuals with ASD does not seem to be necessary.

Key words: Autism, Autism Spectrum Disorders, comorbidity, 2q37, 22q13.3 
FIGURA 1. Fotos da paciente 20 com Síndrome de van der Woude (A e B), sua irmã (C) e seu pai (D). As flechas apontam as fossetas labiais

FIGURA 2. Foto do paciente 23 com diagnóstico de Síndrome do Álcool Fetal.

FIGURA 3. Paciente 37 com aspectos faciais dismórficos, com Síndrome da $\operatorname{del}(5 q)$.

FIGURA 4. Vista fronta (A) e lateral (B) do paciente 45, com Síndrome de Sotos.

FIGURA 5. Paciente 56 com Síndrome da Rubéola Fetal; vista frontal (A) e lateral (B).

FIGURA 6. Paciente 70 com quadro clínico decorrente de Anóxia

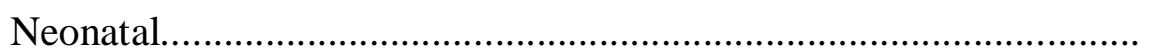

FIGURA 7. Fotos em vista frontal (A) e lateral (B) do paciente 71 
QUADRO 1. Caracterização da casuística quanto ao sexo, idade (em anos) e diagnóstico de DEA. ( $\mathrm{F}=$ feminino; $\mathrm{M}=$ masculino $)$

QUADRO 2. Procedimentos realizados em cada caso e resultados obtidos ( $\mathrm{X}=$ procedimento realizado; $\mathrm{NR}=$ procedimento não realizado; $\mathrm{AR}=$ ausência $\quad$ de resultado; $\mathrm{N}=$ normal; $\mathrm{M}=$ mutação; $\mathrm{CM}=$ condição médica associada).

QUADRO 3. Afecções associadas ao diagnóstico de 


\section{Sumário}

1. INTRODUÇÃO .................................................................................................. 17

1.1 Os Transtornos Invasivos do Desenvolvimento.................................................. 18

1.2 Genética das Doenças do Espectro Autístico....................................................... 22

1.3 Regiões 2q37 e 22q13.3 em DEA.................................................................... 24

1.4 Condições médicas associadas com comportamento autístico............................ 26

2. OBJETIVOS …............................................................................................................... 28

3. MATERIAL E MÉTODOS

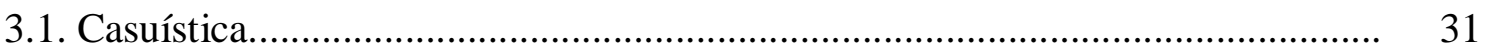

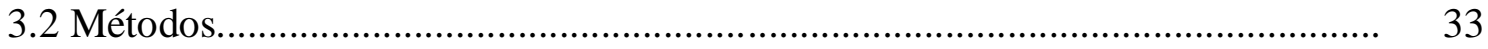

3.2.1 Cultura de Linfócitos e Bandamento GTG................................................... 34

3.2.2 - Hibridização in situ Fluorescente (FISH)................................................... 35

3.2.3. Estudo Molecular.................................................................................................. 36

3.2.3.1 Extração de DNA de leucócitos................................................................... $\quad 36$

3.2.3.2 - Investigação de mutações no gene FMR-1 ............................................ 37

3.2.4. Investigação de afecções associadas............................................................ 39

4. RESULTADOS........................................................................................................... 40

4.1. Estudo Citogenético.............................................................................................. 41

4.2. Estudo Molecular............................................................................................. 42

4.3 Investigação de afecções associadas.................................................................... 44

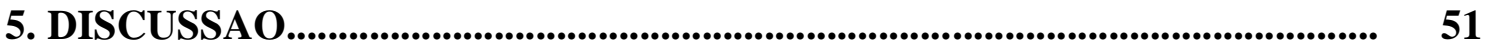

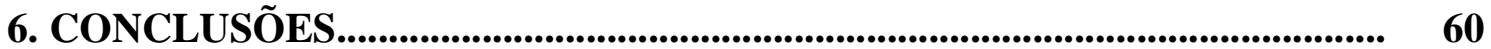

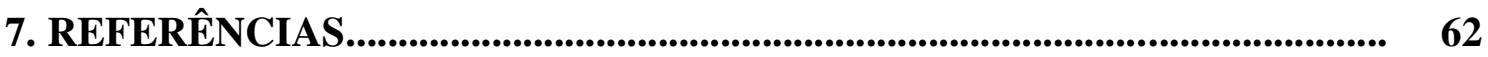

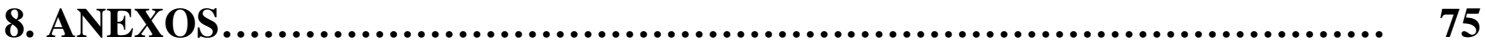

Anexo A. Termo de Consentimento Livre e Esclarecido......................................... 76

Anexo B. Artigo já publicado. Genetics and Molecular Research, v. 7, n. 2, p. 527-

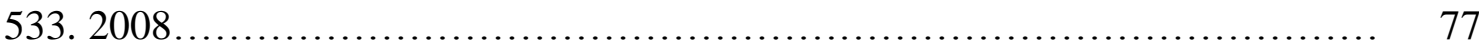

Anexo C. Artigo submetido ao Journal of Autism and Developmental Disorders em fase de correção solicitada pelo editor 


\section{INTRODUÇÃO}

\subsection{Os Transtornos Invasivos do Desenvolvimento}

Os Transtornos Invasivos do Desenvolvimento (TID), do inglês Pervasive Developmental Disorders (PDD), fazem parte de um grupo de condições neuropsiquiátricas da infância (STEINE; GUERREIRO; MARQUES-DE-FARIA, 2003). São definidos como aqueles que interferem no desenvolvimento emocional e cognitivo do indivíduo e se caracterizam por prejuízo grave de áreas do desenvolvimento, como a capacidade de interação social recíproca e de comunicação ou presença de comportamento, interesses e atividades restritos e esteriotipados (APA, 1994). São comuns na população, pois correm em cerca de 60 a cada 10.000 crianças (CHAKRABARTI; FOMBONNE, 2005), e as deficiências qualitativas se manifestam pelo desvio acentuado em relação ao nível de desenvolvimento ou idade do indivíduo (FOMBONNE, 2003).

Os PDDs incluem os seguintes diagnósticos: Síndrome de Asperger, Síndrome de Rett, Transtorno Desintegrativo da Infância, Transtorno Invasivo do Desenvolvimento Sem Outra Especificação (Pervasive Developmental Disorders, Not Otheerwise - PDD-NOS) e Autismo (APA, 1994; STEINE; GUERREIRO; MARQUES-DE-FARIA, 2003).

A identificação dos PDD e suas manifestações seguem os critérios diagnósticos descritos no Manual Estatístico e Diagnóstico da Associação Americana de Psiquiatria quarta edição (DSM- IV). O Código Internacional de Doenças, volume 10, (CID-10) inclui também outras duas categorias, Autismo Atípico e Transtorno Hiperativo Associado com Deficiência Intelectual e Movimentos Estereotipados (CARVALHEIRA; VERGANI; BRUNONI, 2004, SCHMIDT et al., 2008).

As características clínicas são variáveis entre os afetados, mas aproximadamente 75\% apresentam retardo mental e mais de 30\% apresentam epilepsia, o que sugere a ocorrência de dano cerebral. São doenças graves, de etiologia complexa, heterogênea e pouco conhecida. Dentre os diagnósticos destaca-se o Autismo, pela sua precocidade de manifestação e maior freqüência populacional (STEINE; GUERREIRO; MARQUESDE-FARIA, 2003). 
Os PDD são doenças comportamentais com um espectro de manifestações muito semelhantes entre si, o que dificulta o diagnóstico diferencial, que muitas vezes é difícil e pode ser influenciado pela subjetividade do observador. A classificação do DSM IV é a mais utilizada em todo o mundo e está em vigor há mais de 10 anos. Vem sendo questionada, justamente por não incluir algumas peculiaridades dos quadros comportamentais, o que tem estimulado uma considerável quantidade de pesquisas e desenvolvimento de testes diagnósticos (BOSA, 2006; GUPTA;STATE, 2006; SEGENRICH;MATTOS, 2007; BENÍTEZ-BURRACO, 2008; LOSH et al., 2008), a maioria não validada no Brasil .

Particularmente, como a dificuldade no diagnóstico diferencial é maior entre a Síndrome de Asperger, PDD-NOS e Autismo, estas três condições foram incluídas em um subgrupo denominado Doenças do Espectro Autistico - DEA (RUTTER, 2005; CDC, 2007; FOMBONNE, 2009; MULVIHILL, et al, 2009).

Indivíduos com Síndrome de Asperger (SA) têm uma dificuldade substancial em codificar a comunicação não-verbal dos demais. São preocupados, excêntricos e fixados em assuntos específicos. Seus modos podem parecer estranhos pelas suas atitudes e gestos inadequados ao contexto social, além da fala, interpretada como "pedante". Aliás, a ausência de atraso no desenvolvimento da linguagem e o fato dos afetados apresentarem uma memória prodigiosa são aspectos que diferenciam estes indivíduos dos autistas. Além disto, têm a capacidade de reconhecer a sua diferença em relação às outras pessoas e algumas das conseqüências disto, que lamentavelmente muitas vezes são adversas e emocionalmente perturbadoras (TANTAM;GIRGIS, 2009).

Com tantas dificuldades diagnósticas, as descrições de prevalências variam em função dos métodos empregados na seleção das casuísticas. A inclusão da SA nas DEA, a confusão diagnóstica com o chamado "autismo de auto-funcionamento" e mudanças nos critérios diagnósticos dos pesquisadores ao longo do tempo, tornam difícil a comparação entre as taxas descritas (AUSSILLOUX;BAGHDADLI, 2008; FOMBONNE, 2008).

Meta-análises estimam prevalências em torno de 7,1:10.000 para o autismo e 12,9:10.000 para as outras DEA, incluindo a Síndrome de Asperger (WILLIANS;HIGGINS;BRAYNE, 2006). Por outro lado, um estudo finlandês com 5.484 crianças com oito anos de idade estimou uma prevalência de 2,5:1.000 pelos critérios do DSM-IV e 1:370 considerando-se a média obtida com a utilização de diferentes critérios diagnósticos (MATTILA et al., 2007). 
A etiologia é desconhecida em mais de $90 \%$ dos casos e aparentemente muito complexa. Foram descritas mutações em TSC1/TSC2, NF1, PTEN, NLGN3/4, SHANK3, $N R X N 1$, entre outros, e há sugestões de que alterações na homeostase sináptica seja um dos fatores de risco (BOURGERON, 2009). Também há descrições de pacientes com AS e doenças genéticas como Neurofibromatose, Síndrome do Cromossomo X Frágil e Síndrome de Sotos, embora a probabilidade de se observar comorbidade seja maior no Autismo (TANTAM; GIRGIS, 2009).

Embora estudos epidemiológicos sugiram que PDD-NOS seja duas vezes mais comum do que Autismo, esta é uma categoria diagnóstica muito heterogênea, de exclusão, pois como não possui critérios específicos de diagnóstico, é subinvestigada e subdiagnosticada. Entre os clínicos, o índice de "concordância” é relativamente alto no diagnóstico do Autismo, mas o mesmo não ocorre no PDD-NOS (WALKER et al., 2004). Um indivíduo pode ser diagnosticado como PDD-NOS se preencher os critérios do domínio social e mais um dos dois outros domínios (comunicação ou comportamento), mas é possível considerar a condição mesmo se tiver menos do que seis no total, que é o mínimo requerido para o diagnóstico do autismo (MERCADANTE et al., 2006).

Como as crianças com autismo, as crianças com PDD-NOS podem ter interesses restritos, estereotipias, movimentos repetitivos, preocupações ou limitação nos jogos imaginativos, embora geralmente com manifestação menos acentuada. Também em contraste com o autismo, não tem sido observados déficits significativos de linguagem (BRUIN et. al., 2007).

A etiologia deste também não está esclarecida, embora existam inúmeras descrições de associações com síndromes genéticas, genes de predisposição, variação no número de cópias (CNV), condições médicas específicas e ação de diversos agentes disruptivos, como nas demais DEA (SANTANGELO;TSATSANIS, 2005; MERIKANGAS;CORVIN;GALLAGHER, 2009).

O Autismo é a DEA mais estudada e destacada pela literatura, reconhecido como a segunda deficiência do desenvolvimento mais comum em crianças depois do retardo mental (CENTERS FOR DISEASE CONTROL AND PREVENTION, 2009).

Em 1942, Kanner descreveu os "distúrbios autísticos do contato afetivo" que se caracterizavam por introspecção, obsessividade, esteriotipias e ecolalia. Esses sinais indicavam um quadro peculiar, relacionado com as doenças da linha esquizofrênica. Em estudos realizados em 1945, o mesmo autor definiu o Autismo como uma entidade 
clínica singular do grupo de perturbações emocionais graves, na qual os pais dos afetados também apresentavam transtornos emocionais. Em 1956, ainda Kanner, na continuidade de seus estudos, descreveu o Autismo como uma "psicose", cujos exames laboratoriais e clínicos seriam incapazes de fornecer dados que indicassem a etiologia da doença. As mudanças nas definições do quadro autístico começaram a acontecer com Ritvo (1976) que relacionou o autismo a um déficit cognitivo, considerando-o como um distúrbio do desenvolvimento e não mais como uma psicose (ASSUMPÇÃO;PIMENTEL, 2000).

O diagnóstico de Autismo é feito antes dos três anos de idade e requer a presença de distúrbios de interação social; de interesses restritos, padrões estereotipados do comportamento e distúrbios de comunicação. Os autistas apresentam manifestações complexas que incluem déficits qualitativos na interação social, manifestados por dificuldades na comunicação não-verbal, falhas de desenvolvimento das relações interpessoais, dificuldade em compartilhar interesses, falta de reciprocidade social e emocional. Podem ser observados déficits qualitativos na comunicação, como a falta ou atraso no desenvolvimento da fala (não compensada por outros meios), dificuldade de abstração, uso estereotipado de linguagem, inabilidade em iniciar e manter diálogo, aderência inflexível a rotinas e rituais, preocupações persistentes com objetos ou partes deles, estereotipias motoras, agitar de mãos e balançar do corpo, entre outros (NIKOLOV;JONKER;SCAHILL, 2006; BENÍTEZ-BURRACO, 2008; LOSH ET AL., 2008, SINZIG et al., 2008).

O diagnóstico preciso e nas fases iniciais do desenvolvimento infantil pode significar um prognóstico mais otimista, com ganhos significativos, duradouros e relevantes para a melhora da qualidade de vida dos afetados e suas famílias (GADIA et al., 2004; JARVINEN-PASLEY al., 2008). Estudos realizados com autistas e outros PDD mostram grandes evoluções nas habilidades de interação social quando eles são submetidos a programas especializados de desenvolvimento social e de comunicação (MACHADO et al., 2003; CARDOSO;FERNANDES, 2004;).

Como os estudos sobre Autismo têm apresentado, ao longo do tempo, uma evolução no que se refere definição e formas de compreensão, identificando diferentes etiologias, características e graus de gravidade, a tendência atual é reconhecê-lo como um transtorno neuropsiquiátrico, uma síndrome comportamental, de etiologias múltiplas, que se desenvolve na infância precoce e compromete o processo do desenvolvimento infantil (SCHMIDT et al., 2008). 
Além de ser o mais freqüente entre os PDD, o Autismo é um distúrbio comum na população, com descrições que chegam à estimativa de 1:150, com uma proporção de 4,1 homens para cada mulher afetada e aumento na prevalência estimada nos últimos anos (VAN NAARDEN BRAUN, et. al., 2007; FOMBONNE, 2009). Tais estimativas fazem o Autismo parecer cinco vezes mais freqüente que a Síndrome de Down e três vezes mais que o Diabetes Juvenil (MACHADO,et al., 2003).

Embora trabalhos com abordagens multidisciplinares sejam cada vez mais comuns na literatura, a etiologia do Autismo é heterogênea e pouco conhecida. Uma "epidemia" se desenvolveu num curto período de cerca de 20 anos e, provavelmente, estão envolvidos fatores genéticos, ambientais e a observação mais sistematizada por parte dos clínicos (DETH et al., 2008; CURRENTI, 2009).

Portanto, DEA é um conceito complementar às categorias diagnósticas, que representa um grupo complexo de doenças, pois os traços e comportamentos autísticos são mais uma dimensão distribuída ao longo de um contínuo do que categorias bem definidas (LINTAS;PERSICO, 2008).

Indivíduos com DEA podem apresentar convulsões, deficiência mental, alterações cerebrais anatômicas e funcionais, concentração aumentada de serotonina circulante, hiperatividade, impulsividade e desatenção e síndromes genéticas complexas, com envolvimento de fatores etiológicos distintos, inclusive ambientais, isolados e associados (BIGLER et. al., 2007; BRAUNSCHEWING et al, 2008; SING et al., 2008).

\subsection{Genética das Doenças do Espectro Autístico}

A participação de fatores genéticos na etiologia das DEA já está comprovada desde a introdução dos métodos moleculares de investigação e do estabelecimento de estratégias mais adequadas de avaliação clínica (GABIS et. al., 2005; TEJADA, 2006).

Traços autísticos são descritos em parentes de primeiro grau dos afetados, a herdabilidade é estimada em mais de $90 \%$ e os índice de concordância em gêmeos monozigóticos é de 88\%, (PIVEN, 1997; LINTAS;PERSICO, 2008; ROSENBERG, et al., 2009). 
Existem muitas descrições sobre freqüência elevada de outras doenças psiquiátricas em pais de autistas (MURPHY et al., 2000; SASSON et al., 2007), além de escores menores de QI e desempenho fraco em leitura e escrita entre irmãos (FOMBONNE, 2002).

Alguns estudos sugerem que o déficit cognitivo, tendência a isolamento, personalidade muito introvertida e dificuldades afetivas podem ser expressões mais brandas dos genes responsáveis pelas DEA e que, portanto, existe antecipação genética nestas doenças (PIVEN et al., 1994; GIUNCO, 2006; DICHTER;BELGER, 2008, BISHOP et al. 2008).

A investigação da personalidade de pais de autistas, com a utilização de um questionário específico (Broad Autism Phenotype Questionnaire - BAPQ), mostrou que os mesmos apresentam frequiências significativamente maiores do que os controles de personalidade introspectiva, personalidade rígida e linguagem pragmática alterada (HURLEY, 2007). Este espectro fenotípico amplo das DEA, de brandos (broad phenotype) até graves, em muitos casos resultaria de um efeito aditivo de vários genes (BENÍTEZ-BURRACO, 2008; LEVITT;CAMPBELL, 2009).

Condições médicas associadas às DEA são descritas em muitos casos e estas incluem afecções genéticas como as anormalidades cromossômicas e as doenças monogênicas, com destaque para a Síndrome do Cromossomo X Frágil (BENVENUTO et al .,2009).

Mas, apesar dos inúmeros estudos, poucos genes têm sido identificados como certamente envolvidos na etiopatogenia das DEA (RITVO et. al., 1985; HALLMAYER et. al., 2002). Há genes candidatos, localizados em vários cromossomos, especialmente em 2, 7, 15 e X. Entre as regiões propostas estão 2q31, 2q37, 5p15, 7q, 11q25, 15q, 16q22.3, 17p11.2, 18q21.1, 22q11.2, 22q13.3 e Xp22.2-p22.3 (BARTLETT et. al., 2005; SURESH et. al., 2006; VORTSMAN et. al., 2006).

Mutações genéticas no gene NLGN4 (Xp22.33) já foram observadas em casos de retardo mental e/ou comprometimentos gerais do desenvolvimento e na síndrome de Asperger. Também o EN2, localizado em 17q36, foi associado com o fenótipo autístico em casuísticas independentes (DEPIENNE, et al., 2007), além do TPH2(12q-21.1) e do GLO1 (6p21.3) (SACCO et al., 2007; OMIM, 2008). Até os polimorfismos genéticos que conferem atividade reduzida das enzimas necessárias para metabolização do ácido fólico são propostos como fatores de predisposição (ROGERS, 2008, CURRENTI, 2009). 
Muitos dos genes propostos parecem conferir desde malformações físicas menores, até malformações do sistema nervoso central. Assim, a heterogeneidade clínica das DEA reflete sua complexidade genética envolvendo múltiplos lóci, epistasia e interações gene-ambiente (PERSICO;BOURGERON, 2006).

\subsection{Regiões 2q37 e 22q13.3 em DEA}

Interessante que em DEA também foram descritas alterações subteloméricas submicroscópicas, muito difíceis de serem diagnosticadas em uma avaliação cariotípica de rotina. As extremidades distais, ou regiões subteloméricas, do braço longo do cromossomo 2 (2q37) e do 22 (22q13.3) estão alteradas em alguns casos relatados, principalmente com deleções (LUKUSA et. al., 2005, SEGURADO et. al., 2005; VORTSMAN et al., 2006; GALASSO et al., 2008).

Deleções em 2q37 e 22q13 já foram descritas em pacientes com deficiência mental e malformações maiores e menores, considerados normais quando avaliados por técnicas citogenéticas convencionais, mas que apresentaram tais alterações na avaliação por Hibridização in situ Fluorescente - FISH (BAILEY;PHILLIPS;RUTTER, 1996).

A incidência de deleção subtelomérica em 2q37 na população geral não está esclarecida, mas o fenótipo comportamental autístico ocorre em quase um terço dos pacientes com pontos de quebra em qualquer sub-banda de 2q37 (FALK; CASAS, 2007; GALASSO, et al., 2008). Também, após revisão da literatura, Gallasso e colaboradores (2008) encontraram um total de 50 casos de deleções em pacientes com DEA, com pontos de quebra em 2q37.1 (18 casos), 2q37.2 (10 casos) e 2q37.3 (22 casos), e sugeriram vários genes candidatos mapeados nestes locais.

Entre os genes em 2q37 sugeridos como candidatos por vários autores, se destaca o CENTG2 (Centaurin Gamma2 - 2q37.3), pois é expresso em regiões do sistema nervoso central como amígdala, cerebelo e hipocampo, que estão descritas como alteradas em alguns autistas. Apresenta 4.112 pares de bases e codifica uma proteína do citoesqueleto envolvida em processos neuronais múltiplos do desenvolvimento e da maturação cerebral. Algumas mutações detectadas neste gene já foram relacionadas com susceptibilidade ao Autismo, mas seu envolvimento na 
predisposição a esta doença não está esclarecido (LUKUSA et al., 2004; VORSTMAN ,et al., 2006).

Entretanto, os estudos da associação $C E N T G 2 /$ autismo são contraditórios, pois alguns indivíduos fenotipicamente normais apresentam deleções em 2q37, o que mostra a necessidade de investigação de possíveis diferenças crípticas nos tamanhos dos segmentos deletados, de polimorfismos, assim como de outros fatores como penetrância incompleta e imprinting (CASAS et al,. 2004; KITSIOU-TZELI et al., 2007).

A síndrome da microdeleção em 22q13.3, conhecida como Síndrome de PhelanMcDermid ou Monossomia de 22q13, é uma afecção caracterizada por atraso do desenvolvimento, ausência ou atraso grave de fala, hipotonia neonatal, crescimento normal ou acelerado, aspectos faciais dismórficos menores e comportamento autístico (WILSON et al, 2008; DELAHAYE et al., 2009). Entre os três genes mapeados na região critica mínima (do centrômero ao telômero: $S H A N K 3, A C R$ and $R A B L 2 B$ ), o SHANK3 é considerado o responsável pelos sintomas neurocomportamentais (DELAHAYE et al., 2009)

O gene SHANK3, também conhecido como PROSAP2, é responsável por uma proteína de densidade pós-sináptica (PSD) de sinapses excitatórias que pode funcionar como suporte principal formando grandes placas que compõem uma plataforma para a construção de um complexo PSD. No complexo, a proteína shank3 se liga a neuroliginas, que juntas com as neuroxinas, formam um complexo em sinapses glutamatérgicas, que sinaliza moléculas e proteínas do citoesqueleto, presentes nas espinhas dendríticas e no complexo PSD. SHANK3, então, promove a formação, maturação e aumento de espinhas dendríticas, num sistema no qual perturbações em um número potencial de moléculas, isoladas ou em combinação, podem resultar em quadros clínicos comportamentais semelhantes (DURAND et al., 2007; MOESSNER, et al., 2007).

Há estudos que demonstraram uma possível correlação entre mutações ou pequenos rearranjos citogenéticos envolvendo SHANK3 e o fenótipo DEA, principalmente caracterizado por déficits verbal e social graves. Contudo, estas variações foram herdadas de pais saudáveis e também estavam presentes em alguns filhos não afetados, sugerindo que elas podem conferir vulnerabilidade e não que tenham um papel dominante na patogênese das DEA. A penetrância incompleta também poderia explicar sua presença em outros membros não afetados da família e 
alternativamente poderia causar a doença pela ação sinergística com outros genes de susceptibilidade (LINTAS;PERSICO, 2008).

Todas estas informações sobre dados ainda pouco explorados e não esclarecidos, sugerem que alguns indivíduos com DEA podem apresentar alterações subteloméricas submicroscópicas em 2q37 e em 22q13.3, onde estão mapeados genes possivelmente envolvidos na etiologia destas doenças, o que os torna bons candidatos ao screening destas alterações.

\subsection{Condições médicas associadas com comportamento autístico}

Há uma lista em expansão na literatura de condições médicas associadas com DEA, que abrangem de 5 a $37 \%$ dos casos e incluem fatores pré e peri-natais, como embriopatia rubeóloca e ação de álcool fetal. Além das síndromes de microdeleções e outras já citadas nos itens anteriores, há numerosos casos descritos de uma variedade de doenças genéticas em comorbidade com DEA, mas suas freqüências variam amplamente nos diferentes estudos e na maioria dos casos a etiologia é desconhecida (LEVY et al, 2003; CASTERMANS et al., 2004; KAKINUMA;SATO, 2008).

Em cerca de $20 \%$ dos casos são relatadas diversas mutações e síndromes bem definidas, anormalidades cromossômicas e doenças metabólicas. A Síndrome do Cromossomo X Frágil (FRAXA) e Esclerose Tuberosa são as mais comumente observadas, mas também foram descritos pacientes com DEA e Síndrome de Down, Neurofibromatose tipo I, erros inatos do metabolismo, Síndrome de Angelman, de Prader-Willi, Williams, do cromossomo 15q isodicentrico, De Lange, Cohen, MOMO, Associação Charge, entre outras. Algumas destas doenças são raras e não existem dados epidemiológicos sobre elas. A associação se baseia na descrição de pacientes que, além das características da síndrome apresentam DEA, o que pode não se tratar de comorbidade ou associação, mas efeito adicional do defeito genético envolvido (COHEN et al., 2005; ZAFEIRIOU;VERVERI;VARGIAMI, 2007; CHONCHAIVA, W.; et al, 2009).

Os defeitos metabólicos e mitocondriais podem ter efeitos tóxicos sobre as células do cérebro, com perda neuronal ou alteração no sistema de neurotransmissão; alterações do equilíbrio neocortical excitatório/inibitório e do desenvolvimento 
interneuronal ocorrem na Síndrome do X frágil e na Esclerose Tuberosa, e os defeitos cromossômicos e os genes candidatos estão relacionados com alterações nas conexões neurais, crescimento cerebral e morfologia sinaptica e dendrítica. Estes representam o mecanismo patogenéticos prováveis do fenótipo autístico (BENVENUTO, et al., 2009).

A identificação das doenças e a investigação de mecanismos patogenéticos é fundamental na prática clínica e para o Aconselhamento Genético adequado das famílias. Testes metabólicos estão indicados em caso de sintomas específicos, análise citogenética em alta resolução é importante em caso de dismorfias, investigação de FRAXA e até testes de identificação de alterações genômicas cripticas devem ser solicitados, mas as especificações e limitações de cada teste devem ser considerados (DELAHAYE, et al., 2009).

A hipótese científica que foi testada neste estudo é que alguns pacientes com DEA apresentam alterações cromossômicas, inclusive em 2q37 e 22q13.3, que podem ser detectadas por técnicas citogenéticas convencionais ou FISH, ou ainda condições médicas associadas, numa frequiência que justifique sua avaliação rotineira nesta população. 


\section{OBJETIVOS}




\section{OBJETIVOS}

Diante da complexidade das doenças do espectro autístico e do envolvimento de diferentes mecanismos genéticos na sua etiologia, com a possível participação das regiões $2 q 37$ e 22q13.3, o presente trabalho teve como objetivos:

1. Estudar o cariótipo de pacientes com doenças do espectro autístico pela técnica de bandamento GTG;

2. Investigar a região subtelomérica do braço longo do cromossomo 2 (2q37) em pacientes com doenças do espectro autístico, com o uso da técnica de Hibridização in situ Fluorescente (FISH);

3. Investigar a região subtelomérica do braço longo do cromossomo 22 (22q13.3) em pacientes com doenças do espectro autístico, com o uso da técnica de FISH;

4. Investigar a presença de mutação no gene FMRl nos pacientes do sexo masculino;

5. Avaliar a presença de outras afecções de etiologia genética ou ambientais em comorbidade;

6. Investigar as correlações genótipo-fenótipo nos pacientes que apresentarem alterações. 


\section{MATERIAL E MÉTODOS}

\subsection{Casuística}

Em conformidade com as Normas Regulamentadoras em Pesquisa em Seres Humanos, este trabalho foi aprovado pelo CEP da Faculdade de Medicina de São José do Rio Preto e pela CONEP (Processo 25000.015469/2007-59).

Após a obtenção do Termo de Consentimento Livre e Esclarecido (TCLE), de acordo com a Resolução 196/96 (Anexo A), obtido pela pesquisadora responsável pelo estudo ou por sua orientadora, foram inicialmente avaliados e participaram de uma primeira entrevista 84 indivíduos com diagnóstico de Doenças do Espectro Autístico (DEA), segundo os critérios do DSM-IV (APA, 1994) e CID-10, provenientes da Escola Municipal do Autista "Maria Lúcia de Oliveira" (EMA) de São José do Rio Preto-SP, da Associação dos Amigos dos Autistas (AMA) de Ribeirão Preto-SP, do Recanto Tia Marlene de Votuporanga-SP, do Ambulatório de Genética da Faculdade de Medicina de São José do Rio Preto-SP (FAMERP) e de clínicas especializadas de São José do Rio Preto-SP, instituições que já colaboraram com estudos anteriores e estavam cientes e de acordo com este trabalho. Os diagnósticos de DEA foram realizados por psiquiatras, neurologistas e psicólogos, membros de equipes interdisciplinares e especialistas em DEA.

Entre os 84 indivíduos contatados, que foram avaliados clinicamente e quanto aos seus antecedentes, $13(17 \%)$ desistiram de participar do ${ }^{-}$estudo por motivos diversos, entre eles, porque envolvia coleta de sangue. Assim, foram estudados 71 indivíduos, 54 (76\%) eram do sexo masculino e 17 (24\%) do sexo feminino. As idades variaram de 4 a 29 anos $(X=15)$. Quanto ao diagnóstico, 30 (42\%) apresentavam Autismo, 31 (44\%) PDD-NOS e 10 (14\%) Síndrome de Asperger. O Quadro 1 apresenta a caracterização da casuística quanto ao sexo, idade e diagnóstico.

Não foram incluídos no estudo pacientes com doenças genéticas diagnosticadas previamente, aqueles cujas famílias não concordaram em participar e aqueles que, mesmo com autorização do responsável, apresentaram desconforto exacerbado diante do exame físico e/ou da punção venosa, de acordo com orientações dos psiquiatras e psicólogos. 


\begin{tabular}{|c|c|c|c|}
\hline Caso & Sexo & Idade & $\begin{array}{l}\text { Diagnóstico de } \\
\text { DEA }\end{array}$ \\
\hline 1 & $\mathrm{M}$ & 19 & Autismo \\
\hline 2 & M & 25 & Autismo \\
\hline 3 & M & 13 & Asperger \\
\hline 4 & M & 18 & Autismo \\
\hline 5 & M & 26 & Autismo \\
\hline 6 & M & 11 & Asperger \\
\hline 7 & M & 15 & Autismo \\
\hline 8 & M & 11 & PDD-NOS \\
\hline 9 & M & 20 & Autismo \\
\hline 10 & M & 19 & Autismo \\
\hline 11 & $\mathrm{~F}$ & 19 & Asperger \\
\hline 12 & M & 8 & PDD-NOS \\
\hline 13 & $\mathrm{~F}$ & 13 & Autismo \\
\hline 14 & M & 8 & PDD-NOS \\
\hline 15 & M & 13 & Autismo \\
\hline 16 & M & 8 & PDD-NOS \\
\hline 17 & M & 12 & Autismo \\
\hline 18 & M & 19 & Asperger \\
\hline 19 & M & 26 & Autismo \\
\hline 20 & $\mathrm{~F}$ & 8 & Autismo \\
\hline 21 & M & 29 & Asperger \\
\hline 22 & $\mathrm{~F}$ & 11 & PDD-NOS \\
\hline 23 & M & 16 & Autismo \\
\hline 24 & M & 23 & Autismo \\
\hline 25 & M & 24 & Autismo \\
\hline 26 & M & 13 & PDD-NOS \\
\hline 27 & F & 23 & Autismo \\
\hline 28 & M & 19 & Autismo \\
\hline 29 & M & 11 & Autismo \\
\hline 30 & M & 22 & PDD-NOS \\
\hline 31 & M & 13 & PDD-NOS \\
\hline 32 & M & 8 & Autismo \\
\hline 33 & M & 24 & PDD-NOS \\
\hline 34 & M & 7 & Autismo \\
\hline 35 & M & 10 & PDD-NOS \\
\hline 36 & M & 22 & PDD-NOS \\
\hline 37 & F & 27 & PDD-NOS \\
\hline
\end{tabular}

\begin{tabular}{|c|c|c|c|}
\hline Caso & Sexo & Idade & $\begin{array}{c}\text { Diagnóstico de } \\
\text { DEA }\end{array}$ \\
\hline 38 & $\mathrm{~F}$ & 29 & Autismo \\
\hline 39 & F & 18 & Autismo \\
\hline 40 & F & 7 & PDD-NOS \\
\hline 41 & M & 27 & Autismo \\
\hline 42 & $\mathrm{~F}$ & 23 & Autismo \\
\hline 43 & M & 13 & Asperger \\
\hline 44 & M & 7 & PDD-NOS \\
\hline 45 & M & 14 & Asperger \\
\hline 46 & M & 12 & PDD-NOS \\
\hline 47 & $\mathrm{~F}$ & 22 & Asperger \\
\hline 48 & M & 4 & PDD-NOS \\
\hline 49 & M & 5 & PDD-NOS \\
\hline 50 & M & 6 & Autismo \\
\hline 51 & $\mathrm{~F}$ & 10 & PDD-NOS \\
\hline 52 & M & 10 & Autismo \\
\hline 53 & $\mathrm{~F}$ & 20 & Autismo \\
\hline 54 & F & 12 & PDD-NOS \\
\hline 55 & M & 20 & PDD-NOS \\
\hline 56 & M & 16 & Autismo \\
\hline 57 & M & 12 & Autismo \\
\hline 58 & M & 15 & PDD-NOS \\
\hline 59 & M & 14 & Asperger \\
\hline 60 & M & 4 & PDD-NOS \\
\hline 61 & M & 11 & PDD-NOS \\
\hline 62 & M & 6 & PDD-NOS \\
\hline 63 & M & 18 & Asperger \\
\hline 64 & M & 16 & Asperger \\
\hline 65 & M & 12 & PDD-NOS \\
\hline 66 & F & 5 & PDD-NOS \\
\hline 67 & $\mathrm{~F}$ & 6 & PDD-NOS \\
\hline 68 & F & 6 & PDD-NOS \\
\hline 69 & M & 24 & PDD-NOS \\
\hline 70 & M & 17 & PDD-NOS \\
\hline 71 & M & 15 & Autismo \\
\hline
\end{tabular}

Quadro 1. Caracterização da casuística quanto ao sexo, idade (em anos) e diagnóstico de DEA. ( $\mathrm{F}=$ feminino; $\mathrm{M}=$ masculino) 
Aqueles que apresentaram sinais clínicos sugestivos de doenças genéticas monogênicas, cromossomopatias conhecidas ou doenças multifatoriais, além daqueles com exposição gestacional evidente a agentes disruptivos, foram submetidos a exames complementares diversos quando necessário e, uma vez confirmada a presença de outra afecção associada ao diagnóstico comportamental, os afetados não foram submetidos à avaliação citogenética molecular. Os indivíduos do sexo masculino, sempre que possível, foram avaliados quanto a mutações no gene $F M R l$, para investigação da Síndrome do Cromossomo X Frágil.

\subsection{Métodos}

Culturas de linfócitos para investigação da presença de cromossomopatias por bandamento GTG (resolução de 400-500 bandas) foi realizada em todos os indivíduos. A análise das regiões 2 q37 e 22q13.3 foi realizada em metáfases submetidas a técnica de Hibridização in situ Fluorescente (FISH) e a investigação de mutações no gene FMR1 foi feita por Reação em Cadeia da Polimerase (PCR) e/ou Southern Blot. Esta última foi realizada no Laboratório da Dra. Ângela Maria Vianna Morgante (Instituto de Biociências-USP/SP).

Cada paciente foi submetido a uma avaliação genético-clínica para a identificação de possíveis afecções associadas às doenças do espectro autístico. Para tanto, foi utilizado o protocolo padrão de investigação utilizado pelo Serviço de Genética (FAMERP/FUNFARME - Hospital de Base de Rio Preto - SP). Todos os pacientes foram fotografados em vista frontal e lateral.

Todas as hipóteses diagnósticas levantadas, quando não passíveis de confirmação por métodos laboratoriais, foram discutidas com o Prof. Dr. Antonio Richieri Costa - USP/ Bauru e com outros profissionais de outras especialidades.

Cada caso foi identificado durante toda a execução do estudo por um código, que era conhecido apenas pelos responsáveis pelo estudo. 


\subsubsection{Cultura de Linfócitos e Bandamento GTG}

De cada paciente foram coletados cerca de $10 \mathrm{ml}$ de sangue periférico. A coleta foi realizada com seringa estéril descartável, por profissional qualificado.

As culturas de linfócitos foram desenvolvidas por 72 horas, segundo a técnica de Moorhead et al., (1960), com modificações, de acordo com o protocolo utilizado pelo Laboratório de Genética da Faculdade de Medicina de São José do Rio Preto FAMERP/FUNFARME.

Em três frascos de cultivo celular foram colocados $5 \mathrm{ml}$ de meio de cultura RPMI 1640, suplementado com $20 \%$ de soro fetal bovino, penicilina (100U/ml), fitohemaglutinina (PHA-Gibco 0,2 $\mathrm{ml} / 5 \mathrm{ml}$ de meio) e $0,4 \mathrm{ml}$ de sangue periférico.

Para interrupção da divisão celular foi adicionado $0,1 \mathrm{ml}$ de solução de colquicina Houdé (4x10M), que foi reincubado por 30 minutos antes da colheita. Após o bloqueio celular, o material foi centrifugado a 900-1000rpm durante sete minutos, o sedimento hipotonizado com $6 \mathrm{ml}$ de $\mathrm{KCl}$ a $0,075 \mathrm{M}$ por 10 minutos, a $37^{\circ} \mathrm{C}$, e fixado em metanol ácido acético (3:1). A suspensão celular foi, então, gotejada em lâminas limpas, molhadas e geladas.

As lâminas foram submetidas à técnica de bandamento GTG, realizada segundo a técnica de Grouchy e Turleau (1984), com modificações. As lâminas foram mergulhadas seqüencialmente em tampão Sorensen pH6,8; solução de tripsina 0,2\% e solução salina de PBS, respectivamente, por 15 minutos, dois a 10 segundos e um minuto. Posteriormente, foram coradas em solução de Giemsa a $2 \%$ por três minutos e lavadas em água destilada.

O cariótipo convencional de cada indivíduo foi analisado em 20 metáfases submetidas ao bandamento GTG (resolução de 400-500 bandas). Em um projeto paralelo, o cariotípico também foi realizado em alta resolução (resolução mínima de 550 bandas). Todas as análises foram realizadas pela doutoranda e conferidas por outro orientadora, responsável pela conferência de todos os resultados. Para determinação do padrão de resolução de bandas foram selecionados segmentos dos cromossomos maiores (1-3) e o padrão observado foi comparado às representações diagramáticas em diferentes resoluções contidas na ISCN (2009).

Os achados e a descrição dos mesmos seguiram os critérios contidos na ISCN (2009). As metáfases que apresentaram alterações foram fotografadas. 


\subsection{2 - Hibridização in situ Fluorescente (FISH)}

A técnica de FISH foi realizada de acordo com o protocolo de rotina utilizado no Medical Oncology Divison Cancer Center, Denver, Colorado, adaptado às condições do Laboratório de Genética da Faculdade de Medicina de São José do Rio Preto (FAMERP).

Foram utilizadas lâminas limpas, molhadas e geladas onde foram gotejadas cerca de quatro gotas (com pipeta Pasteur) do sedimento obtido da cultura de linfócitos. Estas ficaram em temperatura ambiente até secar. Foram, então, pré-tratadas, sempre à temperatura ambiente, com ácido acético $70 \%$ por 1 minuto. Sofreram três banhos consecutivos em solução salina de PBS 1X, por 2 minutos cada. Em seguida passaram por uma série sucessiva de etanol a 70, 85 e 100\%, por 2 minutos cada e secaram em temperatura ambiente.

Após o pré-tratamento e desidratação, cada lâmina foi incubada com $100 \mu 1$ de um mix de RNAse e solução salina $(1 \mu 1$ de RNAse a $100 \mathrm{Mg} / \mathrm{mL}$ e $100 \mu 1$ de solução salina SSC $2 \mathrm{X}$ ) por um período de 40 minutos, a $37^{\circ} \mathrm{C}$, em uma câmara úmida. Então, o material sofreu três banhos de SSC $2 X$ (ph 7,0 - 7,4) de 3 minutos cada e em seguida realizou-se nova desidratação com a série de etanol (70, 85 e 100\%) por 2 minutos cada e secagem a temperatura ambiente.

As lâminas foram colocadas em uma solução de formaldeído a $4 \%$ aquecida a $72^{\circ} \mathrm{C}$ mais $1^{\circ} \mathrm{C}$ para cada lâmina inserida. Ao término de 2,5-3 minutos, as lâminas foram submetidas a nova série de desidratação com etanol (70, 85 e 100\%), porém, gelado e secaram em temperatura ambiente.

A desnaturação dos cromossomos, preparação da mistura de hibridização e a lavagem pós-hibridização foram realizadas de acordo com as instruções do protocolo das sondas utilizadas.

As sondas utilizadas foram Tel Vysion $2 q$ Spectrum Orange (Vysis) para a região subtelomérica 2q37 (D2S447), CEP 2 Spectrum Orange (Vysis) para a região centromérica do cromossomo 2, controle, e as sondas DiGeorge/VCFS N25 (D22AS75) Region Probe (22q11.2), controle e Subtelomere Specific Probe (22qter, clone N85A3), para 22q13.3 (Cytocell). 
Todos os experimentos foram realizados utilizando-se uma lâmina controle da eficiência da hibridização, já disponível no Laboratório de Genética (de linfócitos de indivíduos doadores de sangue, sem alterações).

As análises foram realizadas por dois observadores que analisaram separadamente cerca de cinco metáfases por lâminas, em microscópio de fluorescência Olympus BX60, equipado com filtro para DAPI, FITC, rodamina e filtro triplo com lâmina HBO 100W.

Para a documentação dos resultados foi utilizado filme 400 asa (KODAK).

Os critérios para análises foram aqueles descritos por Harris et aL (1995) e Eastmond et al (1995).

\subsubsection{Estudo Molecular}

\subsubsection{Extração de DNA de leucócitos}

O DNA genômico de cada indivíduo foi obtido a partir de leucócitos de amostras de sangue venoso periférico, segundo a técnica descrita por MILLER e colaboradores (1998), com modificações.

Foi coletado em vacutainer com EDTA um volume de $5 \mathrm{ml}$ de sangue periférico. Em um tubo de polipropileno de $15 \mathrm{ml}$ foram adicionados $3,5 \mathrm{ml}$ de FICOLL PAQUE e $5 \mathrm{ml}$ de sangue periférico, este último, transferido com pipeta Pasteur descartável, pela parede do tubo. O material foi então, centrifugado por 30 minutos a 3500rpm. O sobrenadante (plasma) foi retirado e desprezado. O anel de leucócitos foi transferido com pipeta Pasteur descartável para outro tubo e o volume de $15 \mathrm{ml}$ foi completado com PBS 1X. Nova centrifugação foi realizada a 3500rpm por 12 minutos. O sobrenadante foi retirado com pipeta Pasteur descartável; o "pellet" foi ressuspendido e novamente completado o volume de $15 \mathrm{ml}$ com PBS $1 \mathrm{X}$. O material foi centrifugado a 3500rpm por 12 minutos e o sobrenadante recolhido com pipeta Pasteur descartável. O "pellet" de leucócitos foi ressupendido, e em seguida foram adicionados $1 \mathrm{ml}$ de PBS 1X, 3ml de Lysis Buffer, 0,2ml de SDS $10 \%, 50 \mu l$ de proteinase K $(20 \mathrm{mg} / \mathrm{ml})$ e $40 \mu 1$ de RNAse (20mg/ml). O material foi agitado e incubado à $37^{\circ} \mathrm{C}$ overnight. 
Ao "pellet" de leucócitos foi acrescentado $1 \mathrm{ml}$ de $\mathrm{NaCl} 6 \mathrm{M}$ saturado. O tubo foi agitado vigorosamente até formar espuma e colocado no gelo por 15 minutos. O material foi novamente agitado e centrifugado a 3500rpm por 15 minutos. Com pipeta Pasteur, o sobrenadante foi transferido para um novo tubo de $15 \mathrm{ml}$ e completado com $10 \mathrm{ml}$ de etanol absoluto gelado, para a precipitação do DNA. O tubo foi invertido delicadamente até a visualização do DNA precipitado, em forma de fios brancos enovelados. O DNA foi, então "pescado" e colocado em um eppendorf de 1,5ml com $500 \mu 1$ de etanol $70 \%$ gelado. O material foi centrifugado a $14.000 \mathrm{rpm}$ por três minutos, o etanol $70 \%$ foi descartado e o tubo deixado em repouso por 15 minutos. O DNA, em seguida, foi diluído em água estéril e incubado a $37^{\circ} \mathrm{C}$ por três a quatro dias para diluição. Após este período, o material foi dividido em alíquotas e estocado a $-0^{\circ} \mathrm{C}$. A estimativa da concentração foi realizada através de leitura em espectrofotômetro (GeneQuant, Pharmacia), Laboratótio de Imunogenética do HemocentroFUNFARME, gentilmente cedido pelo Prof. Dr. Luiz Carlos de Mattos.

\subsubsection{2 - Investigação de mutações no gene FMR-1}

A investigação do polimorfismo de repetições de trinucleotídeos, presente no gene FMR-1, responsável pela Síndrome do Cromossomo X Frágil, foi realizada segundo a técnica descrita por Haddad e colaboradores (1996), com modificações. Tal técnica consiste na amplificação da região do gene que contém as repetições CGG, por Reação em Cadeia da Polimerase (PCR). O protocolo se baseia no fato de que as mutações completas não sofrem amplificação sob as condições da técnica, que é, portanto, indicativa da presença ou ausência da mutação.

Para tanto, foram utilizados três primers, de seguintes nomes e seqüências:

$\mathrm{f}=5^{\prime}$ agcccegcacttccaccaccagctcctcca $3^{\prime}$

Eag-U = 5' cgacctgtcaccgeccttcagctttcc 3'

Eag-L $=5^{\prime}$ cgctgcgggtgtaaacactgaaaccacgtc 3'

A região polimórfica estava contida dentro da região flanqueada pelos primers $f$ e Eag-U. A região amplificada pelo par Eag-U e Eag- $L$, situa-se a 147 pares de bases cadeia abaixo da região polimórfica, sendo sua amplificação utilizada como controle interno da reação de PCR. 
A reação de PCR foi realizada em volume final de $25 \mu \mathrm{l}$ em microtubos de polipropileno de $0,5 \mathrm{ml}$. Uma mistura inicial de $21 \mu 1$ foi preparada contendo todos os reagentes exceto o DNA genômico e a Taq polimerase. A concentração dos reagentes na mistura final de $25 \mu 1$ foi: $50 \mathrm{mM} \mathrm{KCl}, 10 \mathrm{mM}$ TRIS-HCL, 0,1\% Triton-X-100. 2,0mM

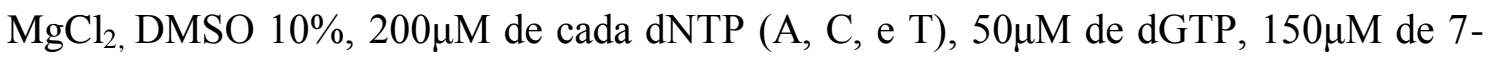
deaza-dGTP (Amersham Pharmacia), $0,08 \mu \mathrm{M}$ primer Eag-L, $0.3 \mu \mathrm{M}$ primer Eag-U e $0,2 \mu \mathrm{M}$ primer $f$.

Foi adicionado a cada tubo, devidamente numerado, uma gota de óleo minera e $21 \mu 1$ do mix preparado. As amostras foram centrifugadas (Spin) para a ressuspensão do mix.

Em seguida adicionou-se à solução $2 \mu \mathrm{l}$ de DNA genômico a 50ng/ $\mu$, ultrapassando a camada de óleo mineral com a ponta da ponteira da micropipeta. Para o grupo de indivíduos investigado foi utilizado um controle positivo (amostra de portador da mutação completa do gene $F M R-1$ ), um negativo e um controle sem DNA (para verificar a ocorrência de contaminação das reações).

Posteriormente, os tubos foram levados ao termociclador e submetidos ao programa HOTXFRA que consiste de $98^{\circ} \mathrm{C}$ por 10 minutos e resfriando a $72^{\circ} \mathrm{C}$ por 3 a 5 minutos. Neste ponto o programa foi interrompido e acrescentado a cada tubo $2 \mu 1$ de um mix de Taq polimerase (Taq DNA Polimerase diluída a $0,8 \mathrm{U} / \mu \mathrm{l}$ em tampão de concentração final de 1X). Imediatamente iniciou-se um outro programa específico de PCR que foi constituído de 35 ciclos, com 90 segundos de desnaturação a $94^{\circ} \mathrm{C}, 60$ segundos de anelamento dos primers a $65^{\circ} \mathrm{C}$ e 2 minutos de extensão a $72^{\circ} \mathrm{C}$, repetidas 35 vezes, com extensão final a $72^{\circ} \mathrm{C}$ por 10 minutos. Após o término da amplificação, as amostras foram estocadas à $4^{\circ} \mathrm{C}$. $\mathrm{O}$ resultado da amplificação foi avaliado por eletroforese em gel de poliacrilamida não-desnaturante a 7,5\%. De cada amostra foram homogeneizados $8 \mu 1$ do amplificado com $2 \mu l$ de azul de bromofenol. Logo após, o homogeneizado foi aplicado no gel de poliacrilamida e submetido à eletroforese em tampão TEB $1 \mathrm{X}$ sob voltagem constante de 100V.

Após o azul de bromofenol ter migrado $7 \mathrm{~cm}$ do topo do gel, a eletroforese foi interrompida e o gel corado segundo o método descrito por Santos e colaboradores (1993), com modificações, que consiste em etapas seqüenciais de fixação (150ml de água, $15 \mathrm{ml}$ de etanol absoluto e $1,15 \mathrm{ml}$ de ácido acético) por 10 minutos, coloração com solução de nitrato de prata a $2 \%(0,3 \mathrm{~g}$ de nitrato de prata e $150 \mathrm{ml}$ de água) por 10 minutos, revelação $(4,5 \mathrm{~g}$ de hidróxido de sódio, $150 \mathrm{ml}$ de água e $450 \mu \mathrm{l}$ de formaldeído) 
por 10 minutos e novamente submetido á fixação. Em seguida o gel foi colocado em papel celofane para secar.

Os indivíduos portadores da Síndrome do Cromossomo X Frágil foram identificados pela ausência da banda polimórfica, que pode variar de 500 a 550pb, revelando a presença da mutação completa. A exclusão do falso positivo foi feita pela presença do controle interno (banda que varia de 200 a 223pb). Os primers Eag- $U$ e $f$ flanqueiam a região de polimorfismo das repetições $\mathrm{CGG}$, produzindo um fragmento de amplificação de tamanho entre 488 a 623pb nos indivíduos normais. Quando ocorre mutação completa, esse fragmento não é obtido, pois as condições da reação de PCR são ineficientes para a amplificação de seqüências longas de DNA. Um fragmento de $223 p b$ é resultante da amplificação da região não polimórfica flanqueada pelos primers Eag- $U$ e Eag-L, interna ao segmento de interesse e que serve como controle da reação da PCR para cada caso.

Casos positivos foram investigados por Souther Blot para confirmação. Alguns foram submetidos diretamente à análise por Souther Blot, por iniciativa e recursos financeiros da própria família.

\subsubsection{Investigação de afecções associadas}

Foi realizada uma entrevista com o responsável, para levantamento da história familial, gestacional e pessoal do paciente, que foi avaliado individualmente, no Ambulatório de Genética do Hospital de Base de São José do Rio Preto e/ou em salas apropriadas das escolas e clínicas já mencionadas. Foram investigadas as características e medidas físicas de cada paciente, sempre pela mesma equipe e coordenada pela Prof ${ }^{\mathrm{a}}$. Dra $^{\mathrm{a}}$. Agnes Cristina Fett Conte. Para este procedimento foi utilizado um protocolo padrão previamente definido pela equipe multidisciplinar do Ambulatório de Genética do Hospital de Base de São José do Rio Preto-SP.

Todos os pacientes foram fotografados em vista frontal e lateral para discussão e provável elucidação de hipóteses diagnósticas. Esta etapa contou com a colaboração de profissionais de diferentes especialidades do próprio Hospital de Base (FAMERP/FUNFARME) e do geneticista e neurologista Dr. Antonio Richieri Costa (USP/BAURU). 
RESULTADOS 


\section{RESULTADOS}

O Quadro 2 apresenta os procedimentos genéticos laboratoriais realizados em cada caso e os resultados obtidos. A avaliação genético-clínica foi realizada nos 71 casos, citogenética convencional em 69, citogenética molecular em 62 e molecular do gene FMR1 em 28.

\subsection{Estudo Citogenético}

Foi realizada cultura de linfócitos para obtenção de metáfases em bandamento GTG dos 71 casos. A avaliação do cariótipo convencional foi possível em 69 (97\%) e o resultado foi compatível com feminino $(46, \mathrm{XX})$ ou masculino $(46, \mathrm{XY})$ normal , dentro dos limites de resolução das técnicas utilizadas em 68 (98,5\%).

Uma paciente (caso 37) apresentou uma alteração cromossômica caracterizada como uma deleção intersticial do braço longo do cromossomo 5 $[46, X X, \operatorname{del}(5)(\mathrm{pter} \rightarrow \mathrm{q} 14:: \mathrm{q} 23 \rightarrow \mathrm{qter})]$

A análise das regiões 2q37 e 22q13.3 por FISH foi realizada em 63 casos selecionados, ou seja, com ausência de fator etiológico conhecido (afecção genética ou ambiental associada). Em alguns casos o resultado não foi obtido por falha de hibridização ou material de qualidade inadequada para FISH em metáfase e impossibilidade de novo cultivo celular.

O resultado foi possível em 59 (94\%) e em 52 (82\%) dos casos, respectivamente, para as regiões $2 \mathrm{q} 37$ e 22q13.3. Nenhum dos casos apresentou alterações subteloméricas detectadas pelas sondas utilizadas, ou seja, todos apresentaram 46,XY.ish 2q37(D2S447x2) ou 46,XY.ish 22q13.3(N85A3x2). 


\subsection{Estudo Molecular}

Entre os 54 pacientes do sexo masculino estudados, 28 (52\%) realizaram estudo molecular por PCR e/ou por Southern Blotting para investigação da Síndrome do Cromossomo X Frágil (Quadro 2).

Não foi possível realizar esta triagem em todos os pacientes porque alguns não apresentaram história familial sugestiva e a técnica de PCR utilizada não respondeu de maneira satisfatória.

\begin{tabular}{|c|c|c|c|c|c|}
\hline Caso & $\begin{array}{c}\text { Avaliação } \\
\text { clínica }\end{array}$ & $\begin{array}{c}\text { Cariótipo } \\
\text { GTG }\end{array}$ & FRAXA & $2 q 37$ & $22 q 13.3$ \\
\hline 1 & $\mathrm{X}$ & $46, X Y$ & $\mathrm{~N}$ & 46,XY.ish 2q37(D2S447x2) & 46,XY.ish 22q13.3(N85A3x2) \\
\hline 2 & $\mathrm{X}$ & $46, X Y$ & $\mathrm{~N}$ & 46,XY.ish 2q37(D2S447x2) & $46, X Y . i s h 22 q 13.3(N 85 A 3 \times 2)$ \\
\hline 3 & $\mathrm{X}$ & $46, X Y$ & $\mathrm{~N}$ & 46,XY.ish 2q37(D2S447x2) & 46,XY.ish 22q13.3(N85A3x2) \\
\hline 4 & $\mathrm{X}$ & $46, X Y$ & $\mathrm{~N}$ & 46,XY.ish 2q37(D2S447x2) & $46, X Y . i s h 22 q 13.3(N 85 A 3 \times 2)$ \\
\hline 5 & $\mathrm{X}$ & $46, X Y$ & $\mathrm{~N}$ & 46,XY.ish 2q37(D2S447x2) & $46, X Y . i s h 22 q 13.3(\mathrm{~N} 85 \mathrm{~A} 3 \mathrm{x} 2)$ \\
\hline 6 & $\mathrm{X}$ & $46, X Y$ & $\mathrm{~N}$ & 46,XY.ish 2q37(D2S447x2) & $46, X Y . i s h 22 q 13.3(\mathrm{~N} 85 \mathrm{~A} 3 \mathrm{x} 2)$ \\
\hline 7 & $\mathrm{X}$ & $46, X Y$ & $\mathrm{~N}$ & 46,XY.ish 2q37(D2S447x2) & NR \\
\hline 8 & $\mathrm{X}$ & $46, X Y$ & $\mathrm{AR}$ & 46,XY.ish 2q37(D2S447x2) & 46,XY.ish 22q13.3(N85A3x2) \\
\hline 9 & $\mathrm{X}$ & $46, X Y$ & $\mathrm{AR}$ & 46,XY.ish 2q37(D2S447x2) & $46, X Y . i s h 22 q 13.3(\mathrm{~N} 85 \mathrm{~A} 3 \mathrm{x} 2)$ \\
\hline 10 & $\mathrm{X}$ & $46, X Y$ & $\mathrm{AR}$ & 46,XY.ish 2q37(D2S447x2) & NR \\
\hline 11 & $\mathrm{X}$ & $46, X X$ & NR & 46,XX.ish 2q37(D2S447x2) & $46, X X$.ish 22q13.3(N85A3x2) \\
\hline 12 & $\mathrm{X}$ & $46, X Y$ & AR & 46,XY.ish 2q37(D2S447x2) & $46, X Y . i s h 22 q 13.3(\mathrm{~N} 85 \mathrm{~A} 3 \mathrm{x} 2)$ \\
\hline 13 & $\mathrm{X}$ & $46, \mathrm{XX}$ & NR & 46,XX.ish 2q37(D2S447x2) & NR \\
\hline 14 & $\mathrm{X}$ & $46, X Y$ & $\mathrm{aR}$ & 46,XY.ish 2q37(D2S447x2) & NR \\
\hline 15 & $\mathrm{X}$ & $46, X Y$ & $\mathrm{~N}$ & 46,XY.ish 2q37(D2S447x2) & $46, X Y . i s h 22 q 13.3(\mathrm{~N} 85 \mathrm{~A} 3 \mathrm{x} 2)$ \\
\hline 16 & $\mathrm{X}$ & $46, X Y$ & $\mathrm{~N}$ & 46,XY.ish 2q37(D2S447x2) & NR \\
\hline 17 & $\mathrm{X}$ & $46, X Y$ & $\mathrm{~N}$ & 46,XY.ish 2q37(D2S447x2) & $46, X Y . i s h 22 q 13.3(\mathrm{~N} 85 \mathrm{~A} 3 \times 2)$ \\
\hline 18 & $\mathrm{X}$ & $46, X Y$ & $\mathrm{~N}$ & 46,XY.ish 2q37(D2S447x2) & $46, X Y . i s h 22 q 13.3(\mathrm{~N} 85 \mathrm{~A} 3 \times 2)$ \\
\hline 19 & $\mathrm{X}$ & $46, X Y$ & $\mathrm{AR}$ & 46,XY.ish 2q37(D2S447x2) & $46, X Y . i s h 22 q 13.3(\mathrm{~N} 85 \mathrm{~A} 3 \times 2)$ \\
\hline 20 & $\mathrm{CM}$ & $46, X X$ & NR & NR & NR \\
\hline 21 & $\mathrm{X}$ & $46, X Y$ & $\mathrm{~N}$ & 46,XY.ish 2q37(D2S447x2) & 46,XY.ish 22q13.3(N85A3x2) \\
\hline 22 & $\mathrm{X}$ & $46, X X$ & NR & 46,XX.ish 2q37(D2S447x2) & $46, X X$.ish 22q13.3(N85A3x2) \\
\hline 23 & $\mathrm{CM}$ & $46, X Y$ & $\mathrm{~N}$ & NR & NR \\
\hline 24 & $\mathrm{X}$ & $46, X Y$ & $\mathrm{~N}$ & 46,XY.ish 2q37(D2S447x2) & $46, X Y . i s h 22 q 13.3(\mathrm{~N} 85 \mathrm{~A} 3 \mathrm{x} 2)$ \\
\hline 25 & $X$ & $46, X Y$ & $\mathrm{~N}$ & 46,XY.ish 2q37(D2S447x2) & $46, X Y . i s h 22 q 13.3(\mathrm{~N} 85 \mathrm{~A} 3 \mathrm{x} 2)$ \\
\hline 26 & $\mathrm{X}$ & $46, X Y$ & $\mathrm{~N}$ & 46,XY.ish 2q37(D2S447x2) & $46, X Y . i s h 22 q 13.3(\mathrm{~N} 85 \mathrm{~A} 3 \mathrm{x} 2)$ \\
\hline 27 & $\mathrm{X}$ & $46, X X$ & NR & 46,XX.ish 2q37(D2S447x2) & $46, X X . i s h 22 q 13.3(N 85 A 3 \times 2)$ \\
\hline 28 & $\mathrm{X}$ & $46, X Y$ & $\mathrm{~N}$ & 46,XY.ish 2q37(D2S447x2) & 46,XY.ish 22q13.3(N85A3x2) \\
\hline 29 & $\mathrm{X}$ & $46, X Y$ & $\mathrm{AR}$ & 46,XY.ish 2q37(D2S447x2) & $46, X Y . i s h 22 q 13.3(\mathrm{~N} 85 \mathrm{~A} 3 \mathrm{x} 2)$ \\
\hline 30 & $\mathrm{X}$ & $46, X Y$ & $\mathrm{~N}$ & 46,XY.ish 2q37(D2S447x2) & $46, X Y . i s h 22 q 13.3(\mathrm{~N} 85 \mathrm{~A} 3 \mathrm{x} 2)$ \\
\hline 31 & $\mathrm{X}$ & $46, X Y$ & $\mathrm{~N}$ & 46,XY.ish 2q37(D2S447x2) & $46, X Y . i s h 22 q 13.3(\mathrm{~N} 85 \mathrm{~A} 3 \mathrm{x} 2)$ \\
\hline 32 & $\mathrm{X}$ & $46, X Y$ & AR & 46,XY.ish 2q37(D2S447x2) & 46,XY.ish 22q13.3(N85A3x2) \\
\hline
\end{tabular}

Quadro2. Procedimentos realizados em cada caso e resultados obtidos ( $\mathrm{X}=$ procedimento realizado; $\mathrm{NR}=$ procedimento não realizado; $\mathrm{AR}=$ ausência de resultado; $\mathrm{N}=$ normal; $\mathrm{M}=$ mutação; $\mathrm{CM}=$ condição médica associada). 


\begin{tabular}{|c|c|c|c|c|c|}
\hline Caso & $\begin{array}{l}\text { Avaliação } \\
\text { clínica }\end{array}$ & $\begin{array}{c}\text { Cariótipo } \\
\text { GTG }\end{array}$ & FRAXA & $2 q 37$ & $22 q 13.3$ \\
\hline 33 & $\mathrm{X}$ & $46, X Y$ & $\mathrm{~N}$ & 46,XY.ish 2q37(D2S447x2) & 46,XY.ish 22q13.3(N85A3x2) \\
\hline 34 & $\mathrm{X}$ & $46, X Y$ & $\mathrm{~N}$ & 46,XY.ish 2q37(D2S447x2) & $46, X Y . i s h 22 q 13.3(N 85 A 3 \times 2)$ \\
\hline 35 & $\mathrm{X}$ & $46, X Y$ & $\mathrm{AR}$ & 46,XY.ish 2q37(D2S447x2) & $46, X Y . i s h 22 q 13.3(N 85 A 3 \times 2)$ \\
\hline 36 & $\mathrm{X}$ & $46, X Y$ & AR & NR & $46, X Y . i s h 22 q 13.3(N 85 A 3 \times 2)$ \\
\hline 37 & $\mathrm{CM}$ & $46, X X, 5 q-$ & NR & NR & NR \\
\hline 38 & $\mathrm{X}$ & $46, X X$ & NR & 46,XX.ish 2q37(D2S447x2) & $46, X X . i s h 22 q 13.3(N 85 A 3 \times 2)$ \\
\hline 39 & $\mathrm{X}$ & $46, X X$ & NR & 46,XX.ish 2q37(D2S447x2) & $46, X X . i s h 22 q 13.3(N 85 A 3 \times 2)$ \\
\hline 40 & $\mathrm{X}$ & $46, X X$ & NR & 46,XX.ish 2q37(D2S447x2) & NR \\
\hline 41 & $\mathrm{X}$ & $46, X Y$ & $\mathrm{AR}$ & 46,XY.ish 2q37(D2S447x2) & $46, X Y . i s h 22 q 13.3(N 85 A 3 \times 2)$ \\
\hline 42 & $\mathrm{X}$ & $46, X X$ & NR & 46,XX.ish 2q37(D2S447x2) & $46, X X$.ish $22 q 13.3(\mathrm{~N} 85 \mathrm{~A} 3 \times 2)$ \\
\hline 43 & $\mathrm{X}$ & $46, X Y$ & $\mathrm{AR}$ & 46,XY.ish 2q37(D2S447x2) & $46, X Y$.ish $22 q 13.3(\mathrm{~N} 85 \mathrm{~A} 3 \times 2)$ \\
\hline 44 & $\mathrm{X}$ & $46, X Y$ & $\mathrm{~N}$ & 46,XY.ish 2q37(D2S447x2) & $46, X Y . i s h 22 q 13.3(N 85 A 3 \times 2)$ \\
\hline 45 & $\mathrm{CM}$ & $46, X Y$ & AR & NR & NR \\
\hline 46 & $\mathrm{X}$ & $46, X Y$ & $\mathrm{~N}$ & 46,XY.ish 2q37(D2S447x2) & $46, X Y . i s h 22 q 13.3(\mathrm{~N} 85 \mathrm{~A} 3 \times 2)$ \\
\hline 47 & $\mathrm{X}$ & $46, X X$ & NR & 46,XX.ish 2q37(D2S447x2) & $46, \mathrm{XX}$.ish $22 \mathrm{q} 13.3(\mathrm{~N} 85 \mathrm{~A} 3 \mathrm{x} 2)$ \\
\hline 48 & $\mathrm{X}$ & $46, X Y$ & $\mathrm{AR}$ & 46,XY.ish 2q37(D2S447x2) & $46, X Y . i s h 22 q 13.3(\mathrm{~N} 85 \mathrm{~A} 3 \times 2)$ \\
\hline 49 & $\mathrm{X}$ & $46, X Y$ & $\mathrm{AR}$ & 46,XY.ish 2q37(D2S447x2) & $46, X Y . i s h 22 q 13.3(N 85 A 3 \times 2)$ \\
\hline 50 & $\mathrm{X}$ & $46, X Y$ & AR & NR & $46, X Y . i s h 22 q 13.3(N 85 A 3 \times 2)$ \\
\hline 51 & $\mathrm{X}$ & $46, X X$ & NR & 46,XX.ish 2q37(D2S447x2) & $46, X X . i s h 22 q 13.3(N 85 A 3 \times 2)$ \\
\hline 52 & $\mathrm{X}$ & $46, X Y$ & $\mathrm{AR}$ & 46,XY.ish 2q37(D2S447x2) & NR \\
\hline 53 & $\mathrm{X}$ & $46, X X$ & NR & 46,XX.ish 2q37(D2S447x2) & $46, X X . i s h 22 q 13.3(N 85 A 3 \times 2)$ \\
\hline 54 & $\mathrm{X}$ & $46, X X$ & NR & 46,XX.ish 2q37(D2S447x2) & $46, X X . i s h 22 q 13.3(N 85 A 3 \times 2)$ \\
\hline 55 & $\mathrm{X}$ & $46, X Y$ & $\mathrm{AR}$ & $46, X Y . i s h$ 2q37(D2S447x2) & $46, X Y . i s h 22 q 13.3(N 85 A 3 \times 2)$ \\
\hline 56 & $\mathrm{CM}$ & NR & NR & NR & NR \\
\hline 57 & $\mathrm{X}$ & $46, X Y$ & $\mathrm{AR}$ & 46,XY.ish 2q37(D2S447x2) & $46, X Y . i s h 22 q 13.3(N 85 A 3 \times 2)$ \\
\hline 58 & $\mathrm{X}$ & $46, X Y$ & $\mathrm{AR}$ & 46,XY.ish 2q37(D2S447x2) & $46, X Y . i s h 22 q 13.3(\mathrm{~N} 85 \mathrm{~A} 3 \times 2)$ \\
\hline 59 & $\mathrm{X}$ & $46, X Y$ & AR & 46,XY.ish 2q37(D2S447x2) & $46, X Y . i s h 22 q 13.3(N 85 A 3 \times 2)$ \\
\hline 60 & $\mathrm{X}$ & $46, X Y$ & $\mathrm{~N}$ & 46,XY.ish 2q37(D2S447x2) & NR \\
\hline 61 & $\mathrm{X}$ & $46, X Y$ & $\mathrm{AR}$ & 46,XY.ish 2q37(D2S447x2) & NR \\
\hline 62 & $\mathrm{X}$ & $46, X Y$ & $\mathrm{~N}$ & 46,XY.ish 2q37(D2S447x2) & $46, X Y . i s h 22 q 13.3(N 85 A 3 \times 2)$ \\
\hline 63 & $\mathrm{X}$ & $46, X Y$ & AR & NR & $46, X Y . i s h 22 q 13.3(N 85 A 3 \times 2)$ \\
\hline 64 & $\mathrm{X}$ & $46, X Y$ & $\mathrm{AR}$ & 46,XY.ish 2q37(D2S447x2) & $46, X Y . i s h 22 q 13.3(N 85 A 3 \times 2)$ \\
\hline 65 & $\mathrm{X}$ & $46, X Y$ & AR & 46,XY.ish 2q37(D2S447x2) & NR \\
\hline 66 & $\mathrm{X}$ & $46, X X$ & NR & $46, X X$ ish 2q37(D2S447x2) & $46, X X . i s h 22 q 13.3(\mathrm{~N} 85 \mathrm{~A} 3 \times 2)$ \\
\hline 67 & $\mathrm{X}$ & $46, X X$ & NR & $46, X X$ ish 2q37(D2S447x2) & $46, X X . i s h 22 q 13.3(\mathrm{~N} 85 \mathrm{~A} 3 \times 2)$ \\
\hline 68 & $\mathrm{X}$ & $46, X Y$ & $\mathrm{AR}$ & NR & NR \\
\hline 69 & $\mathrm{CM}$ & $46, X Y$ & M & NR & NR \\
\hline 70 & $\mathrm{CM}$ & NR & $\mathrm{N}$ & NR & NR \\
\hline 71 & $\mathrm{CM}$ & $46, X Y$ & $\mathrm{~N}$ & NR & NR \\
\hline
\end{tabular}

\subsection{Investigação de afecções associadas}

A avaliação clínica mostrou que muitos pacientes apresentaram sinais clínicos dismórficos menores, mas não puderam ser relacionados a condições médicas ou doenças genéticas específicas. 
Entre os 71 casos avaliados, oito (11.3\%) apresentaram afecções genéticas ou ambientais em associação (concluídas ou presumidas) com o diagnóstico de DEA. O Quadro 3 apresenta os casos com DEA e afecções diagnosticadas em associação.

\begin{tabular}{|ccc|}
\hline Caso & Diagnóstico & Afecções Associadas \\
\hline 20 & Autismo & Síndrome de van der Woude \\
23 & Autismo & Síndrome do Álcool Fetal \\
37 & PDD-NOS & Síndrome do 5q- \\
45 & Asperger & Síndrome de Sotos \\
56 & Autismo & Síndrome da Rubéola Fetal \\
69 & PDD-NOS & Síndrome do Cromossomo X Frágil \\
70 & PDD-NOS & Anóxia Neonatal \\
71 & Autismo & Síndrome do Álcool Fetal \\
\hline
\end{tabular}

Quadro 3. Afecções associadas ao diagnóstico de DEA.

\section{Caso 20}

A paciente 20, autista, apresentou atraso do desenvolvimento neuro-psicomotor (ADNPM), fossetas do lábio inferior, hipodontia, ausência de incisivos centrais, caninos e pré molares, fenda palatina, fenda uvular, peito escavado, brida na mão direita, entre outros (Figura 1A e B)...

O diagnóstico foi de Síndrome de Van der Woude(OMIM 119300). O pai e a irmã apresentavam a mesma síndrome, com expressividade suave, caracterizada apenas pelas fossetas labiais (Figura 1C e D). 




Figura 1. Fotos da paciente 20 com Síndrome de van der Woude (A e B), sua irmã (C) e seu pai (D). As flechas apontam as fossetas labiais.

\section{Caso 23}

O paciente 23 apresentou ADNPM, hipotonia, irritabilidade e "nervosismo" desde o nascimento, hirsurtismo, hiperatividade, deficiência de crescimento $(\mathrm{P}<3 \%)$, aurículas proeminentes, pescoço curto, fendas palpebrais curtas e oblíquas para cima, filtrum naso labial longo, clinodactilia do quinto quirodactilo bilateral, entre outros (Figura 2).

A mãe referiu ter ingerido bebidas alcoólicas durante toda a gestação, diariamente. O diagnóstico foi de Síndrome do Álcool Fetal 


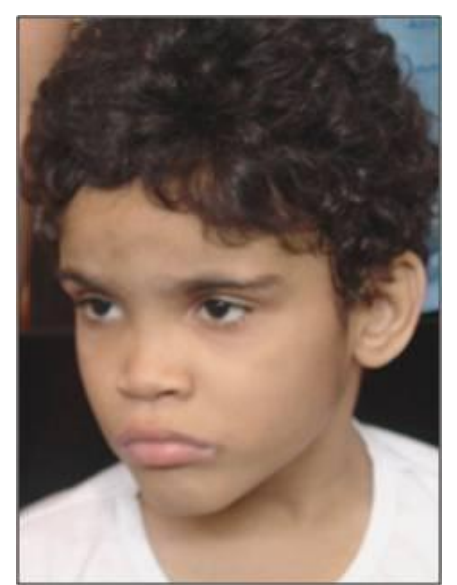

Figura 2. Foto do paciente 23 com diagnóstico de Síndrome do Álcool Fetal.

\section{Caso 37}

A paciente 37 apresentou ADNPM grave, fronte alta e protuberante, microcefalia $(\mathrm{P}<3 \%)$, fendas palpebrais curtas, hipertelorismo ocular, epicanto bilateral, narinas antevertidas, ponte nasal larga, filtrum naso labial longo, microretrognatia, anomalias ordodônticas, pescoço curto, cardiopatia congênita, braquidactilia em mãos e pés, alterações esqueléticas diversas, entre outros (Figura 3).

O cariótipo revelou uma deleção do braço longo do cromossomo 5 $[46, X X, \operatorname{del}(5)($ pter $\rightarrow$ q14::q23 $\rightarrow$ qter $)]$ e o diagnóstico foi de Síndrome da del(5q).



Figura 3. Paciente 37 com aspectos faciais dismórficos, com Síndrome da del(5q) 


\section{Caso 45}

O paciente 45, com Asperger, apresentou cardiopatia congênita, ADNPM, macrossomia, déficit da coordenação motora, hipotonia, hiperreflexia, macrocefalia ( $\mathrm{P}>98 \%$ ), idade óssea avançada, fronte proeminente, dolicocefalia, implantação alta dos cabelos na fronte, inclinação palpebral inferior, hipertelorismo ocular, nistagmo, palato alto, erupção prematura dos dentes, genu valgo, unhas finas, mandíbula proeminente, entre outros. O diagnóstico foi de Síndrome de Sotos (OMIM 117550) (Figura 4).

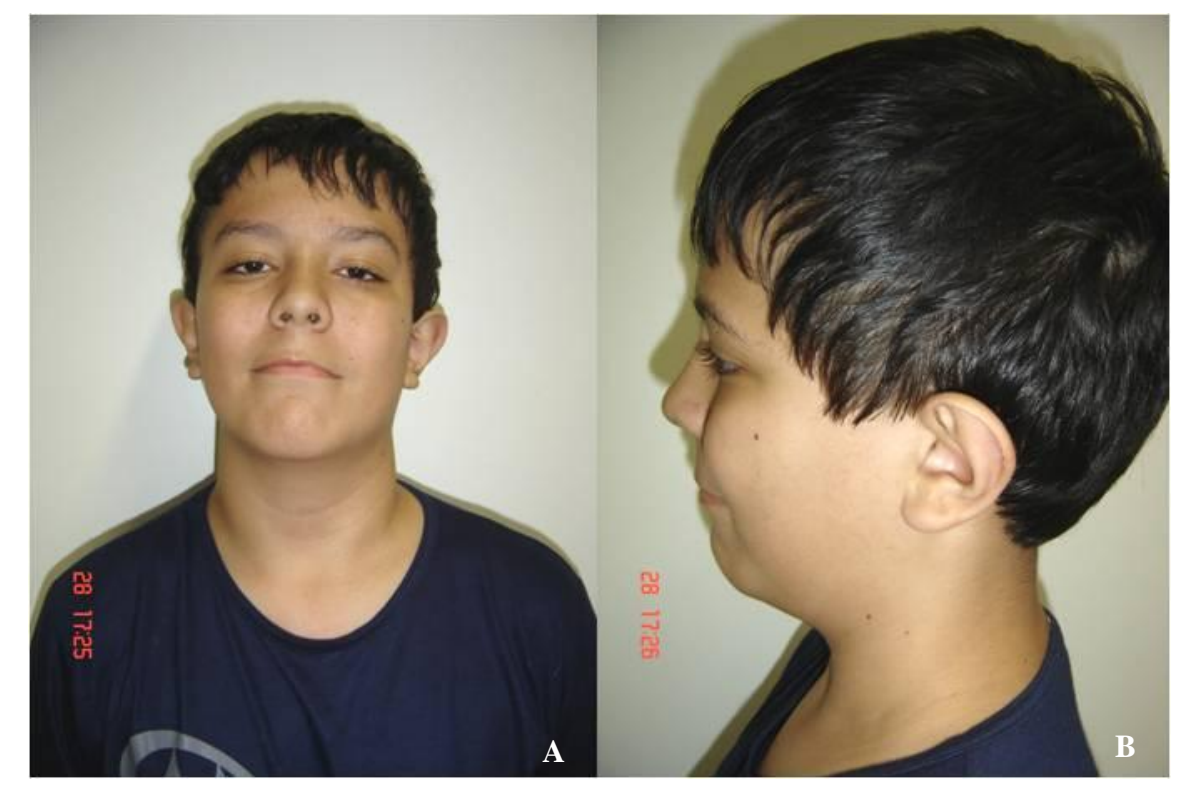

Figura 4. Vista fronta (A) e lateral (B) do paciente 45, com Síndrome de Sotos.

\section{Caso 56}

O paciente 56, autista, apresentou hipotonia, ADNPM grave, deficiência de crescimento $(\mathrm{P}<10 \%)$, microcefalia $(\mathrm{P}<2 \%)$, pé-torto congênito bilateral, surdez profunda bilateral, entre outros. Nasceu a pré-termo (cerca de 28 semanas) e a mãe relata ter tido rubéola (confirmada por testes imunológicos) no primeiro trimestre da gravidez. O diagnóstico foi de Síndrome da Rubéola Fetal (Figura 5). 




Figura 5. Paciente 56 com Síndrome da Rubéola Fetal; vista frontal (A) e lateral (B).

\section{Caso 69}

O paciente 69 apresentou alterações eletroencefalográficas, atraso do desenvolvimento neuro-pesico-motor (ADNPM), fácies alongado, estrabismo convergente à esquerda, hipotonia, orelhas grandes com cartilagem macia, fendas palpebrais oblíquas para cima, ponte nasal larga, prognatismo, cifose, macrogenitalismo, entre outros. Além do comportamento autístico, apresentava episódios de auto agressão (mordedura das mãos) .

O diagnóstico foi de Síndrome do Cromossomo X Frágil e se baseou na alteração detectada pela técnica de PCR, seguida da confirmação por Southern Blot, compatíveis com mutação completa do gene FMRl.

\section{Caso 70}

O paciente 71 apresentou redução difusa da substância branca cerebral, aumento de ventrículos cerebrais, encefalopatia difusa e epilepsia focal, ADNPM grave, hipotonia, alterações motoras, punhos cerrados, occipital plano, orelhas grandes e em abano, cifose e peito escavado. O paciente tem paralisia cerebral e o diagnóstico foi de seqüelas de Anóxia Neonatal (Figura 6). 


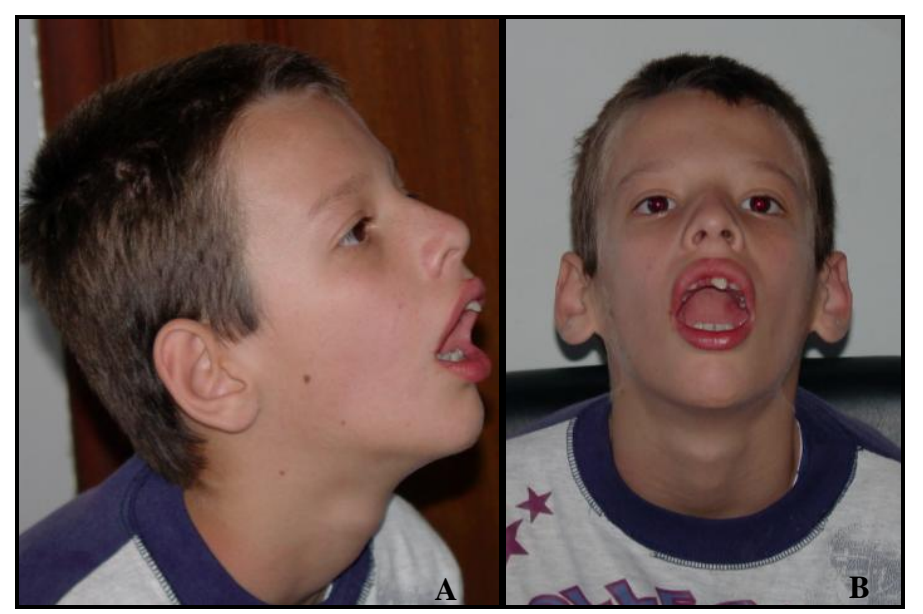

Figura 6. Paciente 70 com quadro clínico decorrente de Anóxia Neonatal.

\section{Caso 71}

O paciente 71 presentou ADNPM, hipotonia, irritabilidade, hirsurtismo, hiperatividade, deficiência de crescimento $(\mathrm{P}<3 \%)$, aurículas proeminentes, ptose palpebral bilateral, fendas palpebrais curtas e oblíquas para cima, filtrum naso labial longo, entre outros.

A mãe, com problemas psiquiátricos graves (SIC), ingeriu bebidas alcoólicas diariamente durante toda a gestação, além de drogas ilícitas. O diagnóstico foi de Síndrome do Álcool Fetal (Figura 7A e B). 


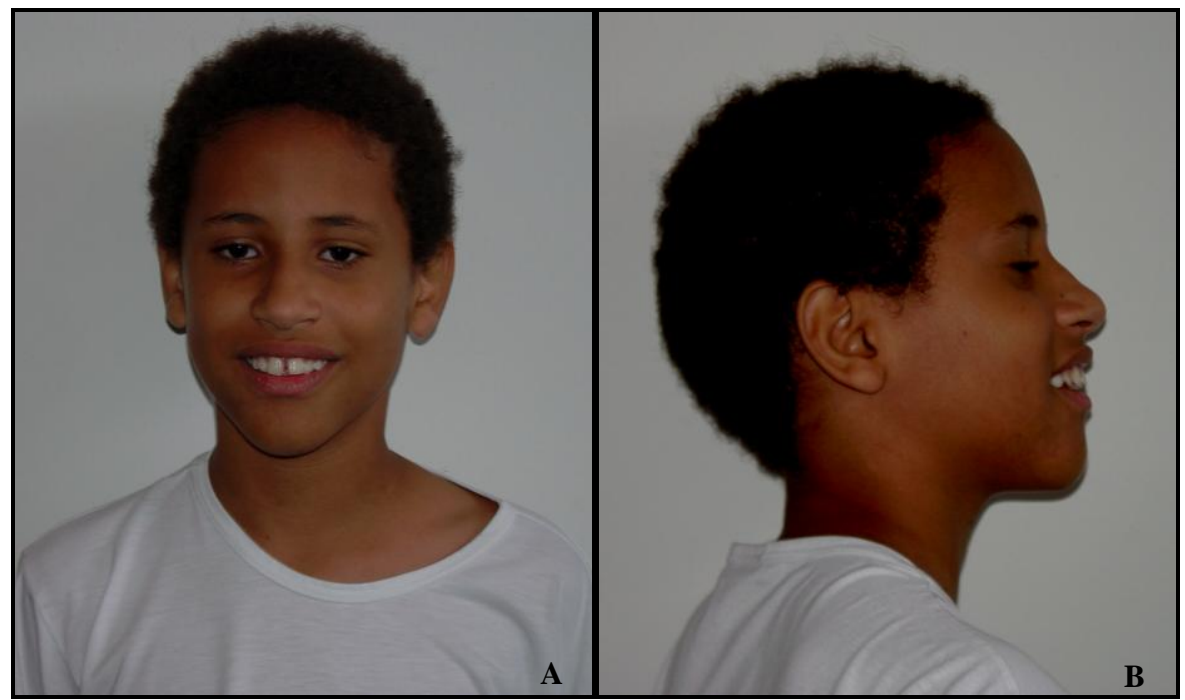

Figura 7. Fotos em vista frontal (A) e lateral (B) do paciente 71.

Este trabalho resultou em cinco artigos científicos: um publicado (Anexo B), um submetido ao Journal of Autism and Developmental Disorders, em fase de correção solicitada pelo editor (Anexo C) e três outros em fase de redação (um sobre afecções médicas associadas a DEA, um sobre van der Woude e autismo e outro sobre del 5q e DEA. 


\section{DISCUSSAO}

Os avanços na investigação molecular têm aumentado o conhecimento da biologia das doenças cognitivas, afetivas e de certas psicoses. Porém, a compreensão dos efeitos das alterações nas funções encefálicas e na fisiopatologia do sistema nervoso é um desafio.

A prevalência progressivamente aumentada e a complexidade das DEA, com a participação de fatores etiológicos tão distintos e de provável efeito aditivo, têm estimulado diversas pesquisas com diferentes estratégias de investigação dos mecanismos biológicos envolvidos. Os fatores genéticos são os mais estudados e têm uma participação inegável na etiologia de muitos casos, o que tem resultado em um aumento significativo no número de encaminhamentos para os geneticistas clínicos (SCHAEFER et al., 2008). Contudo, a literatura está repleta de contradições, pois diferentes estudos observam fatores em algumas casuísticas que não se repetem em outras, prevalências diferentes e uma variação nos métodos utilizados para o mesmo fim, o que dificulta o estabelecimento de protocolos de investigação laboratorial de rotina.

Neste estudo foi proposta a investigação cariotípica, citogenética molecular das regiões 2q37 e 22q13.3, além da investigação da Síndrome do Cromossomo X Frágil nos homens e de possíveis associações do fenótipo comportamental com outras condições médicas.

Muitas alterações citogenéticas têm sido descritas em pacientes com DEA, particularmente nos fenótipos comportamentais mais graves e com aspectos dismórficos. A proposta de investigar anomalias cromossômicas nestes paciente é relatada como um dos procedimentos mais importantes na investigação, pela prevalência observada em algumas casuísticas e pela relevância para o Aconselhamento Genético das famílias (LINTAS;PERSICO, 2009). Tais alterações podem desencadear o quadro autístico por envolverem genes de predisposição ou promoverem condições genéticas para que outras mutações genômicas se expressem. Inclusive, em pacientes com DEA já foram descritas alterações numéricas e estruturais envolvendo todos os pares de cromossomos (DELLA-MÔNICA et al., 2007).

Alterações cromossômicas em DEA são descritas em frequiências que variam de 3 a 6\% (GIUNCO, 2002; DURAND et al., 2007; NEWBURY et al., 2009). Neste 
estudo foi de $1,4 \%$, um pouco abaixo do esperado, mas que pode ter ocorrido em função número pequeno de pacientes estudados.

A paciente apresentou a Síndrome da del(5q) com uma deleção intersticial de q14 a q23. Os aspectos dismórficos foram compatíveis com alguns casos previamente descritos (TZSCHACH et al., 2006). Contudo, não há descrições de pacientes com deleções nesta região e DEA.

Della Mônica e colaboradores (2007) descreveram um paciente autista, com aspectos dismórficos menores, malformações renais e retardo mental, que apresentava uma translocação balanceada de novo envolvendo 1q23 e 5q22 e uma deleção intersticial em 1q. Embora os autores tenham dado mais ênfase à possível relação do autismo com a perda de genes em 1q, 5q22 também pode conter genes relacionados ao quadro autístico e esta região foi alterada também na paciente descrita aqui. Além disso, alguns estudos de ligação sugeriram que $5 q$ é uma região de interesse, que pode conter genes de predisposição ao fenótipo autístico (MA et al., 2007).

Em 5q14-q23 há muitos genes mapeados e há trabalhos que propõem muitos deles como envolvidos na predisposição à epilepsia idiopática, à esquizofrenia e a outras alterações neurocognitivas, como abstração e flexibilidade mental (DEPREZ et al., 2006; ALMASY et al., 2008; NG MY et al 2009). Seu papel no fenótipo autístico, portanto, merece ser melhor investigado.

Mas, embora nos últimos anos muitos loci gênicos tenham sido associados às DEA, poucos genes candidatos têm sido identificados. Talvez pelo fato de que estas doenças não seguem um padrão mendeliano de herança, mas surgem da interação de vários genes (CARVALHEIRA et al., 2004).

Quando se pesquisa os genes candidatos propostos, as regiões $2 \mathrm{q} 37$ e $22 \mathrm{q} 13.3$ surgem como duas das mais importantes, uma vez que há relatos de pacientes com DEA e alterações nestas regiões.

Por exemplo, para alguns autores, alterações subteloméricas submicroscópicas em 2q37 explicariam a causa do fenótipo autístico dos seus pacientes (RIGIEL;SCHINZEL, 2002; SHERR et al., 2005). Na região 2q37, após revisão da literatura, GALLASSO e colaboradores (2008) encontraram um total de 50 casos de deleções com pontos de quebra em 2q37.1 (18 casos), 2q37.2 (10 casos) e 2q37.3 (22 casos), sugerindo alguns genes importantes nessas sub-bandas, como o NMUR, o KIF1A e o HES6, que atuam na modulação da ação dopaminérgica, diferenciação, plasticidade, maturação e manutenção neuronal. Nesta região estão também mapeados o gene $G B X 2$, 
que se expressa na região cerebral anterior, e o gene CENTG2 ou centaurin gamma 2, que se expressa em várias regiões do cérebro fetal (WASSINK, et al., 2005).

O potencial envolvimento destes genes, ainda não muito conhecidos, e a ação sinérgica entre estes e outros genes envolvidos na função, diferenciação e reparo neuronal, podem explicar as variações observadas nos déficits neuropsicológicos associados com a síndrome da deleção em 2q37 e desperta a atenção para o estudo desta região em DEA (BENVENUTO et al., 2009).

As alterações descritas em 2q37 podem estar subestimada na população com DEA e, também, a análise citogenética por bandamento GTG não seria suficiente para detecta-la. Há a necessidade de estudos pela técnica de FISH para a confirmação de resultados (BARBOSA-GONÇALVES et al., 2008; GALASSO et al., 2008), pois nenhuma técnica é conclusiva quando é utilizada isoladamente. A própria análise por FISH com sondas subteloméricas também pode gerar resultados ambíguos que requerem avaliação cuidadosa da intensidade da hibridização do sinal (tamanho do sinal). Apenas discriminar a presença ou ausência dos sinais pode não ser suficiente (LUCIANI, et al., 2003; BONAGLIA, et al., 2005).

Barbosa-Gonçalves e colaboradores (2008) investigaram 20 pacientes com DEA e não observaram alterações em 2q37. Os autores justificam este resultado pelo número pequeno de pacientes analisados e sugeriram a necessidade de estudos com casuísticas maiores antes de propor que a investigação desta região faça parte da rotina de avaliação de pacientes com DEA. O presente trabalho é uma continuação daquele anterior e ampliou a casuística em mais 39 casos, analisados por GTG e FISH considerando todos os aspectos importantes na análise, e nada foi encontrado em 2q37.

Embora cerca de 50\% dos pacientes com a síndrome da deleção em 2q37 apresentem fenótipo autístico, a frequiência desta deleção na população com DEA é desconhecida (LUKUSA et al. 2004), e parece ser muito rara, o que explicaria o resultado obtido.

Neste estudo não foram encontradas alterações em 22q13.3 pelas técnicas utilizadas. Para Phillipe e colaboradores (2008), as deleções 22q13.3 em estão sub diagnosticadas e pouco esclarecidas, e devem ser investigadas na população com DEA. Relacionada a esta região há uma afecção denominada Síndrome da Deleção de 22q13, ou Síndrome de Phelan McDermid, caracterizada, entre outros, por problemas globais do desenvolvimento em $98 \%$ dos afetados, incluindo comportamento autístico (PHELAN, 2008; OMIM, 2009), e diagnosticada por citogenética convencional, 
citogenética molecular e/ou análises moleculares da região cromossômica 22q13, que contém o gene SHANK3/PROSAP2, já associado a problemas de fala, linguagem e relacionamento social (HEILSTEDT et al, 2003; LUCIANI et al., 2003; WILSON et al., 2003).

O gene SHANK3 codifica uma proteína de densidade pós-sináptica (PSD) de sinapses excitatórias envolvida na construção de um complexo PSD, onde se liga a neuroliginas, que juntas com as neuroxinas formam um complexo em sinapses glutamatérgicas, que sinaliza moléculas e proteínas do citoesqueleto, presentes nas espinhas dendríticas e no complexo PSD. SHANK3 promove a formação, maturação e aumento de espinhas dendríticas, num sistema complexo no qual perturbações em um número potencial de moléculas, isoladas ou em combinação, podem resultar em quadros clínicos comportamentais semelhantes (MOESSNER, et al., 2007).

Mas, também, a freqüência de del(22q13.3) na população com DEA é baixa, estimada em 1\% (MANNING et al., 2004; MUKADDES;HERGUNER, 2007), o que explicaria, em parte, o resultado aqui obtido, pois seria necessário a análise de mais 100 casos e foram analisados 52 , além de outras técnicas complementares, porém de custo elevado, como CGH (Comparative Genomic Hybridization) array.

Esta questão metodológica é particularmente importante e todos os resultados têm que leva-la em consideração. Um bom exemplo são os achados de Delahaye e colaboradores (2009), que descreveram a caracterização molecular da del(22)(q13.3). A análise por MLPA mostrou uma discrepância entre os dois kits comerciais utilizados, pois um deles mostrou a deleção e o outro não. FISH com a sonda LSI TUPLE1/LSI ARSA (Vysis) mostrou a deleção, que envolvia o gene ARSA, mas com a sonda N25/N85A3 (Cytocell), cujo alvo é o SHANK3, foi normal. O PCR em tempo real, por sua vez, mostrou que o ponto de quebra ocorreu entre o intron 9 e o exon 22 do gene SHANK. Os dados mostraram a dificuldade da escolha de testes crípticos para investigar esta deleção.

Portanto, alterações cromossômicas subteloméricas crípticas em 2q37 e 22q13 em pacientes com DEA parecem ser muito mais raras do que se supõe, ou muito difíceis de serem diagnosticadas. Isto sugere que a avaliação destas regiões no screening de pacientes ou nos protocolos de investigação laboratorial de rotina deve ser questionada, especialmente na ausência de sinais clínicos outros compatíveis com as síndromes de deleções destas regiões. 
Investigar condições médicas associadas também é importante na patogênese das DEA. Algum autor tem chamado os quadros autísticos associados a uma causa conhecida de "autismo sindrômico", que correspondem a cerca de 10\% dos casos de DEA e frequentemente apresentam dismorfias. Podem estar associados com síndromes genéticas bem conhecidas, rearranjos cromossômicos e injurias provocadas por agentes ambientais (LINTAS;PERSICO, 2009).

Neste estudo, tais associações foram detectadas em $11 \%$ dos casos estudados, o que corrobora os dados da literatura. As doenças genéticas foram uma alteração cromossômica já discutida anteriormente, a Síndrome de Van der Woude, de Sotos e Síndrome do Cromossomo X Frágil, e as ambientais foram Síndrome do Álcool Fetal, da Rubéola Fetal e Anóxia Neonatal.

Esta é a primeira descrição da Síndrome de Van der Woude associada com autismo. Tal síndrome, também conhecida como Síndrome da Fosseta Labial ou da Fosseta Labial com Fissura de Lábio/Palato e Cisto labial, é a mais freqüente entre os casos de fissura labial e/ou palatina, tem padrão autossômico dominante, alta penetrância e expressividade variável (SPRINTZEN et al., 1980; WANG et AL, 2003; RIZOS;SPYROPOULOS, 2004). A incidência é de aproximadamente 1 em 35-60.000 nascidos vivos, sem preferência por sexo (MATSUDA et al, 2004; JEHEE, et al., 2009; MARTELLI-JUNIOR et AL, 2009;).

O gene responsável é o IRF6 (fator 6 regulador do interferon), que está mapeado em $\underline{1 \mathrm{q} 32-\mathrm{q} 41}$ e 30 a 50\% dos casos apresentam mutações de novo (OMIM, 2010).

Kondo e colaboradores (2002) realizaram análises dos genes por O IRF6 faz parte de uma família de nove fatores de transcrição que compartilham um domínio altamente conservado e regula a expressão do interferon alfa e beta após infecção viral (O’NEILL, 2006). Este gene não foi relacionado a fenótipo autismo, mas mutações em IRF6 também podem causar a Síndrome do Pterígio Pplíteo, que apresenta algumas características em comum com a Van der Woude (PREYRARD-JANVID et AL, 2005).

O quadro autístico pode fazer parte do espectro fenotípico da síndrome, porém esta sugestão necessita de estudos complementares. O fato do pai e da irmã da paciente aqui estudada também serem afetados pode ser explicado pela expressividade variável.

A Síndrome de Sotos, que também foi observada em um dos pacientes, é conhecida como uma macrossomia, idade óssea avançada, características faciais típicas, ADNPM e alterações comportamentais. São relatadas várias alterações cerebrais, como anomalias do ventrículo cerebral, do corpo caloso, do espaço extracerebral 
supratentorial (JONES, 2007). A doença resulta de mutações dominantes no gene NSD1 (nuclear receptor binding SET domain protein 1 gene), em mais de 90\% dos casos, que na maioria das famílias são esporádicos (KOTILAINEN, ET AL.,2009).

O gene está mapeado em 2q35 e a descrição de vários casos de Sotos em pacientes com autismo e macrocefalia (SCHAEFER;LUTZ, 2006; BATTAGLIA;CAREY, 2006), levaram à sugestão de que o NSD1 poderia estar envolvido em outros casos de autismo sem a síndrome (SCHAEFER;LUTZ, 2006; BATTAGLIA;CAREY, 2006). Contudo, Buxbaum e colaboradores (2007) analisaram 88 pacientes com diagnóstico de DEA e macrocefalia e sugeriram que a síndrome de Sotos é uma causa rara de DEA, portanto, que o screening para mutações e deleções no gene NSD1 em pacientes com DEAe macrocefalia não está justificada na ausência de outras características da síndrome. No paciente aqui estudado, a etiologia do quadro autístico, portanto, pode ser relacionada ao quadro clínico esperado da síndrome.

A síndrome do Cromossomo X Frágil, por sua vez, é uma doença mais freqüente em homens, com um espectro broad que inclui problemas cognitivos e comportamentais de vários graus, associados com características físicas distintas e não muito consistentes. Estudos recentes mostram que aproximadamente 20-40\% das crianças com a síndrome têm DEA e entre aquelas com DEA, cerca de 2-5\% têm a síndrome (OLIVEIRA et AL, 2004; HANGERMAN;HARRIS,2008). Neste estudo foi observado um caso da doença entre 28 (4\%) pacientes homens avaliados molecularmente, ou seja, dentro do esperado. Pode ser sugerido que a frequiência obtida esteja subestimada, uma vez que apenas pacientes homens foram investigados, embora nenhuma das pacientes estudadas tivesse história familial sugestiva da doença.

Em mais de $98 \%$ dos casos, a síndrome resulta da expansão (>200) de uma repetição de trinucleotídeos CGG na região 5' não traduzida (5'UTR), seguida por metilação e silenciamento do gene FMRl (Fragile X Mental Retardation-1), mapeado em Xq27.3, com subseqüente déficit ou ausência de FMRP (Fragile X Mental Retardation Protein), provavelmente por alterações na metilação da região promotora. A proteína e importante para o desenvolvimento normal do cérebro e sua deficiência leva a espinha dendríticas imaturas, sinaptogênesis alterada, especialmente no córtex cerebral, cerebelo, hipocampo e mais especificamente na plasticidade sináptica (HAGERMAN, 2006; NAUMANN, et al._2009; ASHWOOD et al, 2010).

È certo que o quadro autístico do paciente aqui estudado resultou da mutação completa do gene FMRl. É muito importante determinar na avaliação rotineira se um 
indivíduo com a síndrome tem DEA e vice-versa (LINTAS;PERSICO, 2009), porque o diagnóstico de DEA conduzirá a tratamentos mais específicos e inclusão em programas de intervenção precoce para melhorar a qualidade de vida do paciente e de sua família (OZONOFFO, 2003).

Além dos problemas de etiologia genética, há inúmeros fatores ambientais propostos como causadores do comportamento autístico, principalmente porque elevariam o risco de DEA. Entre eles são relatadas complicações da gestação e do parto (KINNEY et al., 2010).

Neste estudo quatro casos sugeriram efeito disruptivo provocado por agentes ambientais que podem resultar em danos cerebrais e, consequentemente, no fenótipo comportamental autístico, dois pela exposição gestacional ao etanol (Síndrome do Álcool Fetal), um ao vírus da rubéola e um por anóxia neonatal e paralisia cerebral.

Há múltiplos efeitos relatados do álcool sobre o desenvolvimento do embrião e/ou feto, incluindo o desfecho mais grave de todo o espectro: a Síndrome do Álcool fetal. Entre os sinais típicos estão a deficiência de crescimento, disfunção do sistema nervoso central (dificuldade de aprendizagem, retardo mental, etc) e dismorfismos faciais (STRICKLAND et AL., 2007).

A consequiência mais séria da exposição pré-natal ao álcool são os problemas de desenvolvimento e função cerebral. Anomalias neurocomportamentais são frequentemente observadas em crianças expostas ao álcool no período pré-natal, muitas vezes com exame físico completamente normal, entretanto, o comportamento autístico é pouco relatado (JONES, 2007). A associação da exposição gestacional ao álcool com DEA, contudo já foi sugerida (MILLES, et al., 2003) e tal exposição não pode ser descartada como causa do fenótipo autístico dos pacientes aqui estudados.

A Síndrome da Rubéola Fetal é uma consequiência devastadora da infecção por rubéola na gravidez, cujos mecanismos de ação sobre o concepto são pouco esclarecidos. Aborto espontâneo, morte fetal e uma série de defeitos de nascimento podem ser sequelas de tal infecção. São esperados problemas oculares, auditivos, retardo mental, além de outras consequiências sistêmicas (DUSZAK, 2009).

Assumpção-Junior e Kuczynski (2002) relataram um paciente que teve exposição gestacional ao vírus da rubéola e apresentava autismo infantil, transtorno bipolar e retardo mental. Outros autores confirmaram a associação e atribuíram o quadro autístico a lesões pré-natais no sistema nervoso (LINTAS;PERSICO, 2009), o que pode explicar o caso aqui descrito. Embora anteriormente proposto, tais alterações 
já foram descartadas como resultado da vacinação materna, que também havia sido proposta para explicar a prevalência progressivamente maior de DEA na população (MROZEK-BUDZYN;KIELTYKA, MAJEWASKA, 2009).

A paralisia cerebral (PC) descreve um grupo de distúrbios permanentes do desenvolvimento do movimento e da postura, os quais são atribuídos a distúrbios não progressivos que ocorrem no desenvolvimento fetal ou do cérebro infantil. É uma das doenças mais comuns da infância com uma prevalência de 2 a 5 a cada 1.000 nascidos vivos e, embora a disfunção motora seja a característica clínica da PC, deficiências sensoriais, cognitivas e verbais, além de dificuldade de aprendizagem e problemas de comportamento são comuns. Pessoas com PC podem demonstrar aumento das taxas de instabilidade emocional, irritabilidade, déficits de atenção, impulsividade, habilidades limitadas na resolução de problemas e comportamento autístico, (ROSENBAUM et al., 2006).

Steffenburg (1991) and Barton and Volkmar (1998) não encontraram crianças com PC em duas populações com autismo. No entanto, outros pesquisadores relataram taxas entre $0.8 \%$ e $4.8 \%$ (CHAKRABARTI;FOMBONNE, 2001; KIELINEN, et al, 2004; KILINCASLAN et al., 2009).

Há uma prevalência muito alta relatada por Kilincaslan e colaboradores (2009), que observaram 15\% de PDD (11\% de Autismo e 4\% de PDD-NOS) em uma amostra clínica de crianças e adolescentes com PC e apenas três das 19 crianças avaliadas tinha diagnóstico de PDD antes da avaliação feita pelos pesquisadores. Segundo os mesmos, em crianças diagnosticadas com PC nos primeiros estágios de suas vidas, os problemas de interação social, comunicação verbal e não verbal e de comportamento podem ser ignorados ou considerados como parte da doenças. Assim, um diagnóstico de Autismo ou PDD-NOS pode passar despercebido e a intervenção precoce negligenciada.

As lesões cerebrais do caso de PC observado nesta casuística, provocadas por anóxia no momento do parto explicam o fenótipo comportamental. 


\section{CONCLUSÕES}

Indivíduos com Doenças do Expectro Autístico devem realizar avaliação cariotípica por bandamento GTG para investigação de cromossomopatias.

O comportamento autístico parece ser uma das características da Síndrome da del(5q) e esta é uma das doenças cromossômicas associada com as Doenças do Espectro Autístico.

Alterações cromossômicas subteloméricas crípticas em 2q37 e 22q13.3 em pacientes com DEA parecem ser raras e difíceis de serem diagnosticadas.

A avaliação de 2q37 e 22q13.3 no screening de pacientes ou sua inclusão nos protocolos de investigação laboratorial de rotina não parece ser importante, especialmente na ausência de sinais clínicos dismórficos compatíveis com os das síndromes de deleções destas regiões.

As afecções de etiologia genética e não genética são comuns em indivíduos com Doenças do Espectro Autístico e devem ser investigadas nesta população, como a Síndrome do Cromossomo X Frágil, Síndrome de Sotos, do Álcool Fetal, infecção prénatal por vírus e injúrias neonatais.

O comportamento autístico faz parte das características da Síndrome de Van der Woude, que deve constar entre as afecções genéticas associadas ao Autismo.

Os genes localizados em 5q14-23, o IRF6, NSD1 e o FMR1 podem predispor ao comportamento autístico. 
REFERÊNCIAS 


\section{REFERÊNCIAS}

ALMASYM L.; et al. A genome screen for quantitative trait loci influencing schizophrenia and neurocognitive phenotypes. American Journal of Psychiatry,; v. 165, n. 9, p.1185-1192. Sep, 2008.

AMERICAN PSCYCHIATRIC ASSOCIATION. Diagnostic and Statistical Manual of Mental Disorders.4. ed. Washington (DC): American Psychiatric Asociation, 1994.

ASHWOOD, P.; et al. .Plasma cytokine profiles in Fragile X subjects: Is there a role for cytokines in the pathogenesis? Brain Behaviour Immunology., 2010 Jan 25. [Epub ahead of print]

ASSUMPÇÃO, F. B. J.; PIMENTEL, A. C. Autismo infantil. Revista Brasileira de Psiquiatria, v. 22, n. S2, p. 37-39, 2000.

AUSSILLOUX, C.; BAGHDADLI, A. Asperger syndrome: evolution of the concept and current clinical data. Rev Neurol, v. 164,n. 5,p. 406-413, Paris, May, 2008.

BAILEY, A.; PHILLIPS, W.; RUTTER, M. Autism: towards an integration of clinical, genetic, neuropsychological, and neurobiological perspectives. The Journal of Child Psychology and Psychiatry, v. 37, n. 1, p. 89-126. Jan, 1996.

BARBOSA-GONÇALVES, A.; et al. Subtelomeric region of chromosome 2 in patients with autism spectrum disorders. Genetics and Molecular Research, v. 7, n. 2, p. 527533. Jun, 2008.

BARTLETT, C. W.; et al. Three autism candidate genes: a synthesis of human genetic analysis with other disciplines. International Journal of Developmental Neuroscience, v. 23, n. 2-3, p. 221-234. May, 2005.

BATTAGLIA, A.; CAREY, J. C. Etiologic yield of autistic spectrum disorders: a prospective study. Am J Med Genet C Semin Med Genet, v. 142C, n. 1, p. 3-7. Feb, 2006.

BENEVUTO, A. Recent advances in the pathogenesis of syndromic autisms. International Journal of Pediatric, 2009;2009:198736. Epub 2009 Jun 21. 
BENÍTEZ-BURRACO, A. A. Autism and language: some molecular aspects. Revista de Neurologia, v. 46, n.1,p. 40-48, Jan, 2008.

BENVENUTO, A.; et al. Recent advances in the pathogenesis of syndromic autisms. Internationa Journal of Pediatrics, 2009:198736. Epub 2009 Jun 21.

BIGLER, E. D.; et. al. Superior temporal gyrus, language function, and autism.

Developmental Neuropsychology, v. 31, n. 2,p. 217-238. 2007.

BISHOP, D. V.; et al. Autism and diagnostic substitution: evidence from a study of adults with a history of developmental language disorder. Developmental Medicine \& Child Neurology , v. 50, n. 5, p. 341-345. May, 2008.

BONAGLIA, M. C.; et al. Identification of a recurrent breakpoint within the SHANK3 gene in the 22q13.3 deletion syndrome. Journal of Medical Genetics, v. 43, n. 10, p. 822-828. Oct, 2006.

BOSA, C. A. Autism: psychoeducational intervention. Revista Brasileira de Psiquiatria, v. 28,v. Suppl 1,p. S47-S53, May, 2006.

BOURGERON, T. A synaptic trek to autism. Current Opinion in Neurobiology, v. 19, n. 2, p. 231-234. Apr, 2009.

BRAUNSCHWEIG, D.; et al. Autism: maternally derived antibodies specific for fetal brain proteins. Neurotoxicology, v. 29, n. 2, p. 226-231. Mar, 2008.

BRUIN, E. I.; et al. High rates of psychiatric co-morbidity in PDD-NOS. Journal of Autism Developmental Disorders, v.37, n. 5, p. 877-866, May, 2007.

BUXBAUM, J. D. Mutation analysis of the NSD1 gene in patients with autism spectrum disorders and macrocephaly. BMC Medical Genetics, v. 14, p. 8:68.

CARDOSO, C.; FERNANDES, F. D. The communication of autistic spectrum children in group activities. Pro Fono, v.16, n. 1; p. 67-74. 2004.

CARVALHEIRA, G.; VERGANI, N.; BRUNONI,D. Genetics of Autism. Revista Brasileira de Psiquiatria, v. 26,n. 4,p. 270-272, Dec,2004. 
CASAS, K. A.; et al. Chromosome 2 q terminal deletion reporto $\mathrm{f} 6$ new patients and review of phenotype-breakpoint correlations in 66 individuals. American Journal of Medical Genetics, v. 130A, n. 4, p. 331-339. Nov, 2004.

CASTERMANS, D. Chromosomal anomalies in individuals with autism: a strategy towards the identification of genes involved in autism. Autism, v. 8, n. 2, p. 141-146. Jun, 2004.

CDC - Centers for Disease Control and Prevention Mental Health in the United State: Mental health in the United States: parental report of diagnosed autism in children aged 4-17 years--United States, 2003-2004. MMWR Morbidity and Mortality Weekly Report, v. 55, n.17, p. 481-486, Mai, 2006.

CHAKRABARTI, S.; FOMBONNE, E. Pervasive developmental disorders in preschool children. JAMA, v. 285, n 24, p. 3093-3099. JUN, 2001.

CHAKRABARTI, S; FOMBONNE, E. Prvasive developmental disorders in preschool children confirmation of high prevalence. The American Journal of Psychiatry, v. 162, n. 6, p. 1133-1141. Jun, 2005.

CHONCHAIYA, W.; et al. Broad clinical involvement in a family affected by the fragile X premutation. Journal of Devevelopmantal and Behaviour Pediatry, v. 30, n. 6, p. 544-55. Dec, 2009.

COHEN, D.; et al. Specific genetic disorders and autism: clinical contribution towards their identification. Journal of Autism and Developmental Disorder, v. 35, n. 1, p. 103-106, Feb, 2005.

CURRENTI, S. A. Understanding and Determining the Etiology of Autism. Cell Molecular Neurobiology, v.23. Sep, 2009 [Epub ahead of print]

DELAHAYE, A.; et al. Chromosome 22q13.3 deletion syndrome with a de novo interstitial 22q13.3 cryptic deletion disrupting SHANK3. European Journal of Medical Genetics, v. 52, n. 5, p. 328-332. Oct, 2009.

DELLA MONICA, M.; et al. A case of autism with an interstitial 1q deletion (1q23.324.2) and a de novo translocation of chromosomes 1q and 5q. American Journal of Medical Genetic Part A, v. 143A, n. 22, p. 2733-2777, Nov, 2007. 
DEPIENNE, C.; et al. Autism, language delay and mental retardation in a patient with 7q11 duplication. Journal of Medical Genetics, v. 44, n. 7, p. 452-458. Jul, 2007.

DEPREZ, L.; et al. Genome-wide linkage of febrile seizures and epilepsy to the FEB4 locus at 5q14.3-q23.1 and no MASS1 mutation. Human Genetic, v. 118, n. 5, p. 618625. Jan, 2006.

DETH, R.; et al. How environmental and genetic factors combine to cause autism: A redox/methylation hypothesis. Neurotoxicology, v. 29, n. 1, p. 190-201. Jan, 2008.

DICHTER, G. S.; BELGER, A. Atypial modulation of cognitive control by arousal in autism. Psychiatric Research, v. 164, n. 3, p. 185-197. Dec, 2008.

DURAND, C. M.; et al. Mutations in the gene encoding the synaptic scaffolding protein SHANK3 are associated with autism spectrum disorders. Nature Genetics, v. 39, n. 1, p. 25-27. Jan, 2007.

DUSZAK, R. S. Congenital rubella syndrome--major review. Optometry, v. ;80, n. 1. p. :36-43. Jan, 2009.

EASTMOND, D.; SCHULER, M.; RUPA, D. S. Advantages and limitations of using Fluorescende in situ Hybridization for detection of aneuploid in interphase human cells. Mutation Research, v. 348m n. 4, p. 153-162. 1995.

FALK, R. E.; CASAS, K. A. Chromosome 2q37 deletion: clinical and molecular aspects. American Journal of Medical Genetics C Seminar in Medical Genetics, v. 145C, n. 4, p. 357-371. Nov, 2007.

FOMBONNE, E. Epidemiological surveys of autism and other pervasive developmental disorders: an update. Journal of Autism and Developmental Disorders, v.33, n. 4,p. 365-382. Aug, 2003.

FOMBONNE, E. Epidemiological trends in rates of autism. Molecular Psychiatry, v. 7, n. Suppl2, p. S4-S6. 2002.

FOMBONNE, E. Epidemiology of pervasive developmental disorders. Pediatrics Research, v.65, n. 6, p. 591-598. Jun, 2009. 
FOMBONNE, E. Is autism getting commoner? The British Journal of Psychiatry, v. 193, n. 1, p. 59, 2008.

GABIS, L.; et. al. Autism and epilepsy: cause,consequence,comorbidity,or coincidence? Epilepsy Behaviour, v.7, n. 4, p. 652-656, Dec, 2005.

GADIA, C. A.;TUCHMAN, R.; ROTTA, N. T. Autism and pervasive developmental disorders. Journal of Pediatry, v. 80, n. 2 Suppl, p. S83-S94.

GALASSO, D.; et al. Deletion 2q37: an identificable clinical syndrome with mental retardation and autism. The Journal of Child Neurology, v. 23, n. 7, p. 802-806. Jul, 2008.

GIUNCO, C. T. Estudo Genético-Clínico, Investigação da Síndrome do Cromossomo X Frágil e de Polimorfismos da Apolipoproteína e em Autismo. Tese de doutorado, 30/08/2006.

GROUCHY, J. D. E.; TURLEAU, C. Atlas desmaladies chromosomiques, Paris Expansion Scientifique Francise, 1977.

GUPTA, A. R.; STATE, M. W. Autism: genetics. Revista Brasileira de Psiquiatria, v. 28,n. Suppl 1, p.S29-S38. Jun,2006.

HADDAD, L.; et al. PCR-based test suitable for screening for fragile X syndrome among mentally retarded males. Human Genetics, n. 96, n. 6, p. 808-812. 1996.

HAGERMAN, R. J. Lessons from fragile X regarding neurobiology, autism, and neurodegeneration. J Dev Behav Pediatr, v. 27, n. 1, p. 63-74. Feb, 2006.

HALLMAYER, J.; et al., 2002. On the twin risk in autism. American Journal of Human Genetics, v. 71, n. 4, p. 941-946. Oct, 2002.

HARRIS, S. W.; et al. Autism profiles of males with fragile X syndrome. Am J Ment Retard, v. 113, n. 6, p. 427-438. Nov, 2008.

HEILSTEDT, H. A.; et al. Population data suggest that deletions of 1p36 are a relatively common chromosome abnormality. Clinical Genetics, v. 64, n. 4, p. 310-316. Oct, 2003. 
ISCN (International System for Human Cytogenetic Nomenclatures). Shaffer LG, Tommerup N S. Karger Publisher, Inc., 2009.

JARVINEN-PASLEY al., The relationship between form and functional level receptive prosodic abilities in autism. Journal of Autism and Developmental Disorders, v. 38, n.7, p. 1328-1340. Aug, 2008.

JEHEE, F. S.; ET AL. Novel mutations in IRF6 in nonsyndromic cleft lip with or without cleft palate: when should IRF6 mutational screening be done? American Journal of Medical Genetics A, v. 149A, n. 6, p. 1319-1322. Jun, 2009.

KAKINUMA, H.; SATO, H. Copy-number variations associated with autism spectrum disorder. Pharmacogenomics, v. 9, n. 8, p. 1143-1154. Aug, 2008.

KIELINEN, M.; et al. Associated medical disorders and disabilities in children with autistic disorder: a population-based study. Autism., v. 8, n. 1, p. 49-60. Mar, 2004.

KILINCASLAN, A.; MUKADDES, N. M. Pervasive developmental disorders in individuals with cerebral palsy. Dev Med Child Neurol, v. 51, n. 4, p. 289-294. Apr, 2009.

KINNEY, D. K.; et al. A unifying hypothesis of schizophrenia: Abnormal immune system development may help explain roles of prenatal hazards, post-pubertal onset, stress, genes, climate, infections, and brain dysfunction. Med Hypotheses, v. 74, n. 3, p. :555-563. Mar, 2010.

KITSIOTZELI, S.; et al. Array-CGH analysis and clinical description of 2q37 de novo subtelomeric deletion. European Journal of Medical Genetics, v. 50, n. 1, p. 73-78. Jan-Feb 2007.

KONDO, S.; et al. Mutations in IRF6 cause Van der Woude and popliteal pterygium syndromes. Nature Genetics, v.32, p. 285-289. 2002

KOTILAINEN, J.; Premolar hypodontia is a common feature in Sotos syndrome with a mutation in the NSD1 gene. American Journal of Medical Genetics A, v. 149A, n. 11, p. 2409-2414. Nov, 2009.

LEVITT, P.; CAMPBELL, D. B. The genetic and neurobiologic compass points toward common signaling dysfunctions in autism spectrum disorders. The Journal of Clinical Investigation, v. 119, n. 4, p. 747-754. Apr, 2009. 
LEVY, S. E.; et al. Children with autistic spectrum disorders. I: comparison of placebo and single dose of human synthetic secretin. Archives of Disease in Childhood, v. 88, n. 8, p. 731-736. Aug, 2003.

LINTAS, C.; PERSICO, A. M. Autistic phenotypes and genetic testing: state-of-the-art for the clinical geneticist. Journal of Medical Genetics, v. 46, n. 1, p. 1-8, Jan, 2009.

LINTAS, C.; PERSICO, A. M. Autistic phenotypes and genetic testing: state-of-the-art for the clinical geneticist. Journal of Medical Genetics, v. 46, n. 1, p. 1-8. Aug, 2008.

LOSH, M.;et al. Defining key features of the broad autism phenotype a comparison across parents multiple and single-incidence autism families. American Journal or Medical Genetics Part B Neuropsychiatry Genetic, v. 147B,n. 4, p. 424-433. Jun 2008 .

LUCIANI, J. J., et al. Telomeric $2 q 13$ deletions resulting from rings, simple deletions, and translocations: cytogenetic, molecular, and clinical analyses of 32 new observations. Journal of Medical Genetics, v. 40, p. 690-696. 2003.

LUKUSA, T.; et al. Terminal 2q37 deletion and autistic behavior. Genetic counseling, v. 16, n. 2 , p. $179-180.2005$.

LUKUSA, T; et. al. Deletion 2q37.3 and autism: molecular cytogenetic mapping of the candidate region for autistic disorder. Genetic Counselling, v. 15, n. 3, p. :293-301. 2004.

MA, D. Q.; et al. Dissecting the locus heterogeneity of autism: significant linkage to chromosome 12q14. Molecular Psychiatry, v. 12, n. 4, p. 376-384. Apr, 2007.

MACHADO et al. Anatomical and functional abnormalities of central nervous system in autistic disorder: a MRI and SPECT study. Arquivos de Neuropsiquiatria, v.61, $\mathrm{n}$. 4, p.957-961. Dec, 2003.

MANNING, M. A.; et al. Terminal 22q deletion syndrome: a newly recognized cause of speech and language disability in the autism spectrum. Pediatrics, v. 114, n. 2, p. 451457. Aug, 2004

MARTELLI-JUNIOR, H.; et al. Orofacial features of Treacher Collins syndrome. Med Oral Patol Oral Cir Bucal, v. 14, n. 7, p. :E344-348. Jul, 2009. 
MATTILA, M., L.; et al. An epidemiological and diagnostic study of Asperger Syndrome according four sets of diagnostic criteria. Journal of the American Academy of Child and Adolescent Psychiatry, v. 46, n. 5, p 636-646. May, 2007.

MERCADANTE et al., Saccadic movements using eye-tracking technology in individuals with autism spectrum disorders: pilot study. Arquivos de Neuropsiquiatria, v.64, n. 3A, p. 559-562. Sep, 2006.

MERIKANGAS, A. K.; CORVIN, A. P.; GALLAGHER, L. Copy-number variants in neurodevelopmental disorders: promises and challenges. Trends in Genetics, v. 25, $\mathrm{n}$. 12, p. 536-544. Dec, 2009.

MILES, J. H.; et al. Autism families with a high incidence of alcoholism. Journal of Autism and Developmental Disorders, v. 33, n. 4, p. 403-415. Aug, 2003.

MILLER, S. A.; DYKES, D. D.;POLESKY, H. F. A simple salting out procedure for extracting DNA from human nucleated cells. Nucleic Acids Research, v. 16, n.3, p.1215, 1998.

MOESSNER, R.; et al. Contribution of SHANK3 mutations to autism spectrum disorder. American Journal of Human Genetics, v. 81, n. 6, p. 1289-1297. Dec, 2007.

MOORHEAD PS, et al. Chromosome preparations of leukocytes cultured from human peripheral blood. Exp Cell Res. Sep, 1960.

MROZEK-BUDZYN, D.; KIELTYKA, A.; MAJEWASKA, R. [Lack of association between MMR vaccination and the incidence of autism in children: a case-control study]. Przegl Epidemiol, v. 63,n. 1, p. 107-12. 2009.

MUKADDES, N. M.; HERGUNER, S. Autistic disorder and 22q11.2 duplication. World Journal of Biological Psychiatry, V.8, N. 2, P. 127-130. 2007.

MULVIHILL, B.; et al. Prevalence of autism spectrum disorders - Autism and Developmental Disabilities Monitoring Network, United States, 2006. MMWR. Surveillance summaries : Morbidity and mortality weekly report. Surveillance summaries / CDC, v. 58, n. 10, p. 1-20. Dec, 2009.

MURPHY, M. Personality traits of the relatives of autistic probands. Psychological Medicine, v. 30, n. 6, p. 1411-1424. Nov, 2000. 
NAUMANN, A.; et al. A distinct DNA-methylation boundary in the 5'- upstream sequence of the FMR1 promoter binds nuclear proteins and is lost in fragile $\mathrm{X}$ syndrome. American Journal of Human Genetics, v. 85, n. 5, p. 606-616. Nov, 2009.

NEWBURY, D. F.; et al. Mapping of partially overlapping de novo deletions across an autism susceptibility region (AUTS5) in two unrelated individuals affected by developmental delays with communication impairment. American Journal of Medical Genetics A, v. 149A, n. 4, p. 588-597. Feb, 2009.

NG, M. Y.; et al. Meta-analysis of 32 genome-wide linkage studies of schizophrenia. Molecular Psychiatry, v. 14, n. 8, p. 774-785. Aug, 2009.

NIKOLOV, R.; JONKER, J.; SCAHILL, L. Autistic disorder: current psychopharmacological treatments and areas of interest for future developments. Revista Brasileira de Psiquiatria, v.28, n. Suppl 1, p. S39-46, May, 2006

OMIM. Online Mendelian Inheritance in Man. Disponível em www.ncbi.nlm.nih.gov/omim/. Acesso em 30 de Nov. 2009.

OMIM. Online Mendelian Inheritance in Man. Disponível em www.ncbi.nlm.nih.gov/omim/. Acesso em 30 de jan. 2010.

PERSICO, A. M.; BOURGERON, T. Searching for ways out of the autism maze: genetic, epigenetic and environmental clues. Trends Neuroscience, v. 29, n. 7, p. 349358. Jul, 2006.

PEYRARD-JANVIDM M.; et al. Novel and de novo mutations of the IRF6 gene detected in patients with Van der Woude or popliteal pterygium syndrome. European Journal of Human Genetics, v. 13, n. 12, p. :1261-1267. Dec, 2005.

PHELAN, M. C. Deletion 22q13.3 syndrome. Orphanet Journal of Rare Diseases, v. 27, p. 3-14. May, 2008.

PHILIPPE, A.; et al. Neurobehavioral profile and brain imaging study of the 22q13.3 deletion syndrome in childhood. Pediatrics, v. 122, n. 2, p. 376-382. Aug, 2008.

PIVEN, J. et al. Personality characteristics of the parents of autistic individuals.

Psychological Medicine, v. 24, n. 3, p. 783-795. Aug, 1994. 
PIVEN, J. The biological basis of autism. Current Opinion in Neurobiology, v. 7, $\mathrm{n}$. 5, p. 708-712. Oct, 1997.

RIGIEL, M.; SCHINZEL, A. Duplication of (2)(q11.1-q13.2) in as boy with retardation and cleft lip and palate: another clefting gene locus on proximal 2q? American Journal of Medical Genetics, v. 111, n. 1, p. 76-80. Jul, 2002.

RITVO, E. R.; et al. Concordance for the syndrome of autism in 40 pairs of afflicted twins. The American Journal of Psychiatry, v. 142, n. 1, p. 74-77. Jan, 1985.

ROGERS, E. J. Has enhanced folate status during pregnancy altered natural selectiion and possibly Autism prevalence? A closer look at a possible link. Medical Hypotheses, v. 71, n. 3, p. 406-410. Sep, 2008.

ROOSENBERG, R. E.; et al. Characteristics and concordance of autism spectrum disorders among 277 twin pairs. Archives of Pediatrics \& Adolescent Medicine, v. 163, n. 10, p. 907-914. Oct, 2009.

ROSENBAUM, P.; et al. A report: the definition and classification of cerebral palsy April 2006. Dev Med Child Neurol Suppl, v. 109, p. 8-14. Feb, 2007.

RUTTER, M. Autism: its recognition, early diagnosis, and service implication. Journal Developmental Behaviour Pediatrics,v. 27, n. 2, p. S54-58, Apr, 2006.

SACCO, R.; et al. Case-control and family-based association studies of candidate genes in autistic disorder and its endophenotypes: TPH2 and GLO1. BMC Medical Genetics, v. 8, p. 8-11. Mar, 2007.

SANTANGELO, S. L.; TSATSANIS, K. What is known about autism: genes, brain, and behavior. American Journal of PharmacoGenomics, v. 5, n. 2, p. 71-92. 2005.

SANTOS, F. R.; PENA, S. D. J.; EPPLEN, J. T. Genetic and population study of na Ylinked tetranucleotide repeat DNA polymorphism with a simple non-isotopic techinique. Human Genetics, v. 90, n. 6, p. 655-656. 1993.

SASSON, N.; et al. Orienting to social stimuli differentiates social cognitive impairments in autism and schizophrenia. Neuropsychologica, v. 45, n. 11, p. 25802588. Jun, 2007. 
SCHAEFER, G. B. ; MENDELSOHN, N. J.; NJ; Professional Practice and Guidelines Committee. Clinical genetics evaluation in identifying the etiology of autism spectrum disorders. Genetics in Medicine, v. 10, n. 4, p. 301-305. Apr, 2008.

SCHAEFER, G. B.;LUTZ, R. E. Diagnostic yield in the clinical genetic evaluation of autism spectrum disorders. Genetics in Medicine, v. 8, n. 9, p. 549-56. Sep, 2006.

SCHMIDT, G. L.; et al. Impairments in phonological processing and nonverbal intellectual function in parents of children with autism. Journal of Clinical and Experimental Neuropsycholy,v.30, n. 5, p. 557-567. Jul, 2008.

SEGENRICH,D.; MATTOS, P. Atualização sobre comorbidade entre transtorno do déficit de atenção e hiperatividade (TDAH) e transtornos invasivos do desenvolvimento (TID) / Update on the comorbidity of attention-deficit/hyperactivity disorder (ADHD) and pervasive developmental disorder (PDD). Revista de Psiquiatria Clínica, v. 34, n.4,p. 184-190. 2007.

SEGURADO, R.; et al. Confirmation of association between autism and the mitochondrial aspartate/glutamate carrier SLC25A12 gene on chromosome 2q31. The American Journal of Psychiatry, v. 162, n. 11, p. 2182-2184. Nov, 2005.

SHERR, E. H.; et al. Genomic microarray analysis identifies candidate loci in patients with corpus callosum anomalies. Neurology, v. 65, n. 9, p. 1496-1498. Nov, 2005.

SINZIG, J.; et al. Inhibition, flexibility, working memory and planning in autism spectrum disorders with and without comorbid ADHD-symptoms. Child and Adolescent Psychiatry and Mental Health, v. 31, n. 2, p. 4. Jan, 2008.

STEINER, C. E.; GUERREIRO, M. M.; MARQUES-DE-FARIA, A. P. Genetic and neurological evaluation in a sample of individuals with pervasive developmental disorders. Arquivos de Neuro-psiquiatria, Brasil, v. 61, n. 2, p. 176-80. Jun, 2003.

STRICKLAND, D. C.; et al. An Evolution of Virtual Reality Training Designs for Children With Autism and Fetal Alcohol Spectrum Disorders. Top Lang Disord, v. 27, n. 3, p. 226-241. Jul, 2007.

SURESH, R. New complexities in the genetics of stuttering significant sex-specific linkage signals. American Journal of Human Genetics, v. 78, n. 4, p. 554-563. Apr, 2006. 
TANTAM, D; GIRGIS, S. Recognition and treatment of Asperger Syndrome in the community. British Medical Bulletin, v. 89, p. 41-62. Feb, 2009.

TEJADA, M. I. Rett syndrome: a diasgnostsic, clinical and molecular update. Review of Neurology, v. 42,n. Suppl 1,p. S55-S59, Jan, 2006.

TZASCHACH, A.; et al. Molecular cytogenetic analysis of a de novo interstitial deletion of $5 \mathrm{q} 23.3 \mathrm{q} 31.2$ and its phenotypic consequences. American Journal of Medical Genetic A, v. 140, n. 5, p. 496-502. Mar, 2006.

TZASCHACH, A.; et al. Molecular cytogenetic analysis of a de novo interstitial deletion of 5q23.3q31.2 and its phenotypic consequences. American Journal of Medical Genetics Part A, v. 140, n. 5, p. 496-502. Mar, 2006.

VAN NAARDEN BRAUN, K.; et. al. Evaluation of a methodology for a collaborative multiple source surveillance network for autism spectrum disorders--Autism and Developmental Disabilities Monitoring Network, 14 sites, United States, 2002.

Morbidity and Mortality Weekly Report-Surveillance Summaries, v. 56, n. 1, p. 29-40. Feb, 2007

VORTSMAN, J. A.; et al. Identification of novel autism candidate regions through analysis of reported cytogenetic abnormalities associated with autism. Molecular Psychiatry, v. 11, n. 1, p. 1-18. Jan, 2006.

WALKER, D. R.; et al. Specifying PDD-NOS: a comparison of PDD-NOS, Asperger syndrome, and autism. Journal of the American Academy of Child and Adolescent Psychiatry, v. 43, n. 2, p. 172-80. Feb, 2004.

WASSINK, T. H.; et. al. Evaluation of the chromosome 2q37.3 gene CENTG2 as an autism susceptibility gene. American Journal of Medical Genetics Part B:

Neuropsychiatric Genetics, v. 136B, n. 1, p. 36-44. Jul, 2005.

WILLIANS, J. G.; HIGGINS, J. P.; BRAYNE, C. E. Systematic review of prevalence studies of autism spectrum disorders. Archives of Disease in Childhood - BMJ Journals, v. 91, n. 1, p. 8-15. Jan, 2006.

WILSON, H. L.; et al. Interstitial 22q13 deletions: genes other than SHANK3 have major effects on cognitive and language development. European Journal of Medical Genetics, v. 16, n. 11, p. 1301-1310. Nov, 2008. 
WILSON, H. L.; et al. Molecular characterisation of the 22q13 deletion syndrome supports the role of haploinsufficiency of SHANK3/PROSAP2 in the major neurological symptoms. Journal of Medical Genetics, v. 40, n. 8, p. 575-584. Aug, 2003.

ZAFEIRIOU, D. I.; VERVERI, A.; VARGIAMI, E. Childhood autism and associated comorbidities. Brain Devevelopmental, v. 29, n. 5, p. 257-272, Jun, 2007. 
ANEXOS 


\section{ANEXOS}

Anexo A. Termo de Consentimento Livre e Esclarecido 
Anexo B. Artigo já publicado. Genetics and Molecular Research, v. 7, n. 2, p. 527-533. 2008 .

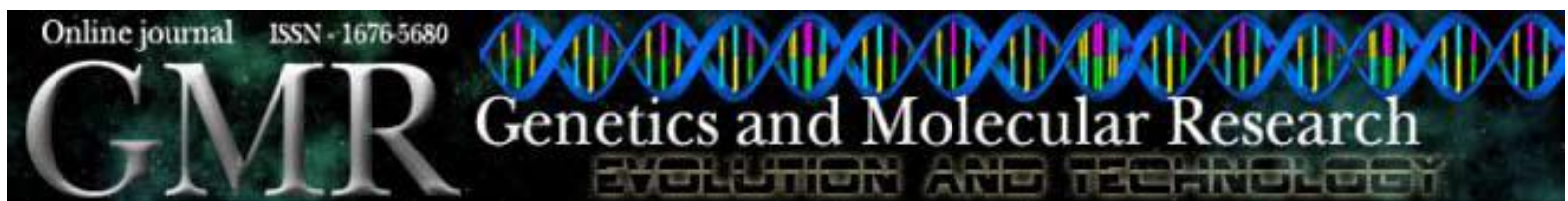

\title{
Subtelomeric region of chromosome 2 in patients with autism spectrum disorders
}

\author{
A. Barbosa-Gonçalves1, C.B. Vendrame-Goloni1, A.L.B. Martins1 \\ and A.C. Fett-Conte2
}

1Departamento de Biologia, Instituto de Biociências,

Letras e Ciências Exatas, Universidade Estadual Paulista,

São José do Rio Preto, SP, Brasil

2Departamento de Biologia Molecular,

Faculdade de Medicina de São José do Rio Preto,

São José do Rio Preto, SP, Brasil

Corresponding author: A.C. Fett-Conte

E-mail: genética@fmerp.br

Genet. Mol. Res. 7 (2): 527-533 (2008)

Received April 22, 2008

Accepted May 26, 2008

Published June 17, 2008

\begin{abstract}
Autism spectrum disorders are severe psychiatric diseases commonly identified in the population. They are diagnosed during childhood and the etiology has been much debated due to their variations and complexity. Onset is early and characterized as communication and social interaction disorders and as repetitive and stereotyped behavior. Austistic disorders may occur together with various genetic and chromosomal diseases. Several chromosomal regions and genes are implicated in the predisposition for these diseases, in particular those with products expressed in the central nervous system. There are reports of autistic and mentally handicapped patients with submicroscopic subtelomeric alterations at the distal end of the long arm of chromosome 2. Additionally, there is evidence that alterations at $2 \mathrm{q} 37$ cause brain malformations that result in the autistic phenotype. These alterations are very small and not identified by routine cytogenetics to which patients are normally submitted, which may result in an underestimation of the diagnosis. This study aimed at evaluating the 2 q37 region in patients with autistic disorders. Twenty patients were studied utilizing the
\end{abstract}

Genetics and Molecular Research 7 (2): 527-533 (2008) 
Genetics and Molecular Research 7 (2): 527-533 (2008)

OFUNPEC-RP www.funpecrp.com.br fluorescence in situ hybridization technique with a specific probe for $2 \mathrm{q} 37$. All of them were also studied by the GTC banding technique to identify possible chromosomal diseases. No alterations were observed in the $2 \mathrm{q} 37$ region of the individuals studied, and no patient presented chromosomal diseases. This result may be due to the small sample size analyzed. The introduction of routine analysis of the $2 \mathrm{q} 37$ region for patients with autistic disorders depends on further studies.

Key words: Autism spectrum disorders; Chromosome 2; Fluorescence in situ hybridization; FISH technique.

\section{INTRODUCTION}

Due to the difficulty in establishing diagnostic boundaries between diseases considered to be invasive development disorders (CID-10; OMS, 1993), such as Asperger's syndrome, nonspecified pervasive development disorders and autism, they are referred to as autistic spectrum disorders (ASDs; CDC, 2006). These are severe psychiatric diseases which are characterized by multiple neurological manifestations that have a heterogeneous etiology which is difficult to elucidate and poorly understood (Bailey et al., 1996; Steiner et al., 2003). These diseases are present at birth, become apparent before 30 months of life and are characterized by abnormal responses to audible and visual stimuli as well as lack of or underdeveloped speech. Individuals have severe problems in social relationships, ritualistic behavior associated with abnormal routines and resistance to change, reduced capacity for abstract and symbolic thoughts or for imaginative games, with intelligence being subnormal, normal or above normal (ABRA, 1994). Most cases (75\%) have mental deficiency (Rutgers et al., 2004), 15 to 40\% convulsions and 20 to $25 \%$ electroencephalographic alterations (Smalley, 1997; Gabis et al., 2005). However, with the exception of Rett syndrome which shows a genetic etiology and in many cases new mutations of the MECP2 gene mapped on Xq28 (Tejada, 2006), the etiology of other pervasive development disorders remains unclear.

ASDs are very complex with participation of genetic factors in their etiology and, in many cases, the influence of environmental factors. The prevalence is estimated at 1-4 cases for every 1000 children with a male to female ratio of 2-4. These numbers have been increasing since the introduction of molecular methods of diagnostic testing and the establishment of more adequate strategies for clinical evaluation (APA, 1994; Smalley, 1997; Gillberg and Wing, 1999; Bertrand et al., 2001). According to some authors, these diseases seem to be more frequent with estimates of up to 1:500 live newborns (Levy et al., 2003; Castermans et al., 2004).

Genetic investigations are essential to understand the etiology and physiopathology of the disease, considered the consequence of some and cause of others (Veenstra-Vanderweele et al., 2004). Concordance in homozygotic twins is $95.7 \%$ and the probability of family recurrence is 75 times greater than in the general population, which implicates a risk of recurrence in cases not associated with a specific etiology estimated at 2.9\% (Ritvo et al., 1985; Hallmayer et al., 2002). Additionally, ASDs, especially autism, which has been the most studied, have also been associated with chromosomal anomalies and with several genetic diseases, in particular with fragile X syndrome (Challman et al., 2003; Muhle et al., 2004; Polleux and Lauder, 2004; Cohen et al., 2005). 
Everything suggests that predisposition to autism involves allelic heterogeneity and heterogeneity of the locus, which may also explain the endophenotypic variability, that is, the measurable components of the disease that are important elements in diagnosis (Gottesman and Gould, 2003; Veenstra-Vanderweele et al., 2004).

Despite the numerous studies, few candidate genes have been identified with certain involvement in the etiopathogenesis of ASDs (Jamain et al., 2003; Hebert et al., 2006). Some potential genes for predisposition are mapped to 3q, 4p, 7q, 13q, 15q, 16p, and chromosome X. Other possible loci that have been suggested are: 2q31, 2q37, 5p15, 11q25, 16q22.3, 17p11.2, 18q21.1, 22q11.2, 22q13.3, and Xp22.2-p22.3 (Junaid and Pullarkat, 2001; Suresh et al., 2006; Vorstman et al., 2006).

Many of these genes seem to confer from minor physical malformations to malformations of the central nervous system, frequently resulting in genetic anticipation due to the broad phenotype highlighted by many authors (Veenstra-Vanderweele et al., 2004; Bartlett et al., 2005; Philippi et al., 2005; Sutcliffe et al., 2005; Bishop et al., 2006; Trikalinos et al., 2006; OMIM, 2007).

Interestingly, submicroscopic subtelomeric alterations have been reported in autism. The distal end of the long arm of chromosome 2 is one of the regions that is possibly altered in some cases (Wolff et al., 2002; Lukusa et al., 2005; Segurado et al., 2005). Alterations at the 2q terminal have also been described in patients who have mental deficiency and major and minor malformations but are considered to be karyotypically normal using conventional cytogenetic techniques, with these alterations only being detected using fluorescent in situ hybridization (FISH) (Riegel and Schinzel, 2002). Detection of these alterations may, apart from contributing to the understanding of biological mechanisms involved in ASDs, help genetic counseling of the families.

The aim of this study was to investigate the subtelomeric region of the long arm of chromosome 2 (2q37) in patients with ASDs.

\section{PATIENTS AND METHODS}

After approval of the Ethics Committee, written informed consent was obtained from the 20 individuals with ASDs according to the criteria of the DSM-IV. These subjects attend the Municipal School of Autism in São José do Rio Preto "Maria Lúcia de Oliveira", AMA in Ribeirão Preto and other specialized schools and clinics. Among the participants, 12 were autistic, two had been diagnosed with Asperger's syndrome and six with non-specified invasive developmental disorder. The diagnoses were made by psychiatrists and psychologists, members of multidisciplinary teams and specialists in ASDs. Patients who presented comorbidities with genetic features or probable environmental factors involved in the etiology of their disease were not enrolled in this study.

Individuals without prior karyotypic investigations were assessed using the GTG banding technique (Grouchy and Turleau, 1977) to test for chromosomal diseases. All participants were submitted to a genetic-clinical investigation and were photographed.

Metaphases for study were obtained from lymphocytes from $5 \mathrm{~mL}$ peripheral blood samples cultured for $72 \mathrm{~h}$ according to the standard protocol utilized by the Genetics Laboratory of the Medicine School in São José do Rio Preto, FAMERP (Moorhead et al., 1960).

The FISH technique was performed using a specific probe for $2 \mathrm{q} 37$ and for the centromeric region of chromosome 2 (control identification). Denaturation of the chromosomes, 530 CFUNPEC-RP www.funpecrp.com.br Genetics and Molecular Research 7 (2): $527-533$ (2008)

A. Barbosa-Gonçalves et al. 
preparation of the hybridization mixture and post-hydridization rinsing were performed according to the guidelines for use of the probes (Vysis).

All experiments were performed utilizing a slide to control the efficiency of hydridization (of lymphocytes from normal individuals) and three or more slides of the study cases.

Analyses were carried out by two researchers who independently analyzed around ten metaphases of each case using an Olympus BX60 fluorescent microscope with filters for DAPI, FITC, rhodamine and a triple filter with an HBO $100 \mathrm{~W}$ light source. The criteria for analysis and description of the results were those reported by Harris et al. (1995) and Eastmond et al. (1995) and contained in ISCN (Schaffer and Tommerup, 2005).

\section{RESULTS}

No alterations of the $2 \mathrm{q} 37$ region were observed in this series. None of the individuals presented chromosomal diseases.

Figure 1 demonstrates a metaphase submitted to the FISH technique, which shows the normal expected result, that is, two centromeric signals which identify chromosome 2 and two subtelomeric signals that specifically identify the $2 q 37$ region.

\section{DISCUSSION}

Some individuals with autism have been described with alterations at $2 q 37$, which implicates $2 \mathrm{q} 37$ as a region of interest for susceptibility to ASDs, with possible candidate genes, in particular CENTG2 (centaurin gamma 2 gene) (Vorstman et al., 2006; Zafeiriou et al., 2007).

Figure 1. Metaphase submitted to the fluorescence in situ hybridization technique demonstrating the four normal signals, two centromeric (large arrows) and two subtelomeric (small arrows), of the $2 \mathrm{q} 37$ region.

Wolff et al. (2002) studied ten autistic children and ten controls evaluating the subtelomeric regions of all chromosomes using a multiprobe system. Among the participants, the only alteration detected was the deletion at $2 \mathrm{q} 37$ in one of the patients. Alterations in this region have been observed by other authors in patients with ASD and dysmorphic clinical signs (Ghaziuddin and Burmeister, 1999; Smith et al., 2001; Lukusa et al., 2004; Sherr et al., 2005; Wassink et al., 2005).

These findings suggest that in $2 \mathrm{q}$ there are genes involved in the etiology of ASDs and that some patients may have submicroscopic subtelomeric alterations that explain the cause of the disorder (Riegel and Schinzel, 2002; Sherr et al., 2005). The alterations described at 2q37 are very slight and may be underestimated in the ASD population, as they cannot be detected by cytogenetic analysis using routing GTG banding, to which the patients are generally submitted in their clinical genetic evaluation. Thus, studies that utilize the FISH technique may be more enlightening.

In our study, however, of the 20 patients assessed by the most adequate technique to investigate $2 q 37$, none showed alterations. This result may have been due to the number of patients analyzed. A possible proposal to introduce the analysis of the $2 \mathrm{q} 37$ region in the protocol of genetic investigation of patients with ASDs depends on further studies with larger sample sizes. 


\section{Acknowledgments}

The authors wish to thank David A. Hewitt for the English translation of this manuscript. Research supported by School of Medicine in São José do Rio Preto (BAP/FAMERP) and the Brazilian Council for Scientific and Technological Research (CNPq, \#3317/2004 and \#141553/2004-9).

\section{References}

ABRA (Associação Brasileira de Autismo) (1994). Política de Atenção à Pessoa Portadora da Síndrome. ABRA, Brasília.

APA (American Psychiatric Association) (1994). Diagnostic and statistical manual of mental disorders (DSM-IV). American Psychiatric Press, Washington DC.

Bailey A, Phillips W and Rutter M (1996). Autism: towards an integration of clinical, genetic, neuropsychological, and neurobiological perspectives. J. Child Psychol. Psychiatry 37: 89-126.

Bartlett CW, Gharani N, Millonig JH and Brzustowicz LM (2005). Three autism candidate genes: a synthesis of human genetic analysis with other disciplines. Int. J. Dev. Neurosci. 23: 221-234.

Bertrand J, Mars A, Boyle C, Bove F, et al. (2001). Prevalence of autism in a United States population: the Brick Township, New Jersey, investigation. Pediatrics 108: 1155-1161.

Bishop DV, Maybery M, Wong D, Maley A, et al. (2006). Characteristics of the broader phenotype in autism: a study of siblings using the children's communication checklist-2. Am. J. Med. Genet. B. Neuropsychiatr. Genet. 141: 117-122.

Castermans D, Wilquet V, Steyaert J, Van de Ven W, et al. (2004). Chromosomal anomalies in individuals with autism: a strategy towards the identification of genes involved in autism. Autism 8: 141-161.

CDC (Centers for Disease Control and Prevention) (2006). Mental health in the United States: Parental report of diagnosed autism in children aged 4-17 years - United States, 2003-2004. MMWR Morb. Mortal. Wkly. Rep. 55: 481-486.

Challman TD, Barbaresi WJ, Katusic SK and Weaver A (2003). The yield of the medical evaluation of children with pervasive developmental disorders. J. Autism Dev. Disord. 33: 187192.

Cohen D, Pichard N, Tordjman S, Baumann C, et al. (2005). Specific genetic disorders and autism: clinical contribution towards their identification. J. Autism Dev. Disord. 35: 103-116.

Eastmond DA, Schuler M and Rupa DS (1995). Advantages and limitations of using fluorescence in situ hybridization for the detection of aneuploidy in interphase human cells. Mutat. Res. 348: 153-162.

Gabis L, Pomeroy J and Andriola MR (2005). Autism and epilepsy: cause, consequence, comorbidity, or coincidence? 532 OFUNPEC-RP www.funpecrp.com.br Genetics and Molecular Research 7 (2): 527-533 (2008) A. Barbosa-Gonçalves et al. 
Epilepsy Behav. 7: 652-656.

Ghaziuddin M and Burmeister M (1999). Deletion of chromosome 2q37 and autism: a distinct subtype? J. Autism Dev. Disord. 29: 259-263.

Gillberg C and Wing L (1999). Autism: not an extremely rare disorder. Acta Psychiatr. Scand. 99: 399-406.

Gottesman II and Gould TD (2003). The endophenotype concept in psychiatry: etymology and strategic intentions. Am. J. Psychiatry 160: 636-645.

Grouchy J and Turleau C (1977). Atlas des Maladies Chromosomiques. Expansion Scientifique Française, Paris.

Hallmayer J, Glasson EJ, Bower C, Petterson B, et al. (2002). On the twin risk in autism. Am. J. Hum. Genet. 71: 941-946.

Harris C, Robinson T, Michalski K and Meisner L (1995). Specimen salvage with FISH. App. Cytogenet. 21: 66-70.

Herbert MR, Russo JP, Yang S, Roohi J, et al. (2006). Autism and environmental genomics. Neurotoxicology 27: 671-684.

Jamain S, Quach H, Betancur C, Rastam M, et al. (2003). Mutations of the X-linked genes encoding neuroligins NLGN3 and NLGN4 are associated with autism. Nat. Genet. 34: 27-29.

Junaid MA and Pullarkat RK (2001). Proteomic approach for the elucidation of biological defects in autism. J. Autism Dev. Disord. 31: 557-560.

Levy SE, Souders MC, Wray J, Jawad AF, et al. (2003). Children with autistic spectrum disorders. I: Comparison of placebo and single dose of human synthetic secretin. Arch. Dis. Child 88: 731-736.

Lukusa T, Vermeesch JR, Holvoet M, Fryns JP, et al. (2004). Deletion 2q37.3 and autism: molecular cytogenetic mapping of the candidate region for autistic disorder. Genet. Couns. 15: 293-301.

Lukusa T, Smeets E, Vogels A, Vermeesch JR, et al. (2005). Terminal 2q37 deletion and autistic behaviour. Genet. Couns. 16: 179-180.

Moorhead PS, Nowell PC, Mellman WJ, Battips DM, et al. (1960). Chromosome preparations of leukocytes cultured from human peripheral blood. Exp. Cell Res. 20: 613-616.

Muhle R, Trentacoste SV and Rapin I (2004). The genetics of autism. Pediatrics 113: e472e486.

OMIM 209850 (Online Mendelian Inheritance in Man) (2007). http:www.ncbi.nlm.nih.gov.

OMS (Organização Mundial da Saúde) (1993). Classificação de transtornos mentais e de comportamento da CID-10: descrições clínicas e diretrizes diagnósticas. ARTMED, Porto Alegre.

Philippi A, Roschmann E, Tores F, Lindenbaum P, et al. (2005). Haplotypes in the gene encoding protein kinase c-beta (PRKCB1) on chromosome 16 are associated with autism. Mol. Psychiatry 10: 950-960.

Polleux F and Lauder JM (2004). Toward a developmental neurobiology of autism. Ment. Retard. Dev. Disabil. Res. Rev. 10: 303-317.

Riegel M and Schinzel A (2002). Duplication of (2)(q11.1-q13.2) in a boy with mental retardation and cleft lip and palate: another clefting gene locus on proximal 2q? Am. J. Med. Genet. 111: 76-80.

Ritvo ER, Freeman BJ, Mason-Brothers A, Mo A, et al. (1985). Concordance for the syndrome of autism in 40 pairs of afflicted twins. Am. J. Psychiatry 142: 74-77.

Rutgers AH, Bakermans-Kranenburg MJ, van Ijzendoorn MH and van Berckelaer-Onnes IA (2004). Autism and attachment: a meta-analytic review. J. Child Psychol. Psychiatry 45: 11231134. 
Schaffer LG and Tommerup N (2005). An International System for Human Cytogenetic Nomenclature. S. Karger, Basel.

Segurado R, Conroy J, Meally E, Fitzgerald M, et al. (2005). Confirmation of association between autism and the mitochondrial aspartate/glutamate carrier SLC25A12 gene on chromosome 2q31. Am. J. Psychiatry 162: 2182-2184.

Sherr EH, Owen R, Albertson DG, Pinkel D, et al. (2005). Genomic microarray analysis identifies candidate loci in patients with corpus callosum anomalies. Neurology 65: 1496-1498.

Smalley SL (1997). Genetic influences in childhood-onset psychiatric disorders: autism and attention-deficit/hyperactivity disorder. Am. J. Hum. Genet. 60: 1276-1282.

Smith M, Escamilla JR, Filipek P, Bocian ME, et al. (2001). Molecular genetic delineation of 2q37.3 deletion in autism and osteodystrophy: report of a case and of new markers for deletion screening by PCR. Cytogenet. Cell Genet. 94: 15-22.

Steiner CE, Guerreiro MM and Marques-de-Faria AP (2003). Genetic and neurological evaluation in a sample of individuals with pervasive developmental disorders. Arq. Neuropsiquiatr. 61: 176-180.

Suresh R, Ambrose N, Roe C, Pluzhnikov A, et al. (2006). New complexities in the genetics of stuttering: significant sex-specific linkage signals. Am. J. Hum. Genet. 78: 554-563.

Sutcliffe JS, Delahanty RJ, Prasad HC, McCauley JL, et al. (2005). Allelic heterogeneity at the serotonin transporter locus (SLC6A4) confers susceptibility to autism and rigid-compulsive behaviors. Am. J. Hum. Genet. 77: 265-279.

Tejada MI (2006). Rett syndrome: a diagnostic, clinical and molecular update. Rev. Neurol. 42 (Suppl. 1): S55-S59.

Trikalinos TA, Karvouni A, Zintzaras E, Ylisaukko-oja T, et al. (2006). A heterogeneity-based genome search meta-analysis for autism-spectrum disorders. Mol. Psychiatry 11: 29-36.533 Veenstra-Vanderweele J, Christian SL and Cook EH Jr (2004). Autism as a paradigmatic complex genetic disorder. Annu. Rev. Genomics Hum. Genet. 5: 379-405.

Vorstman JA, Staal WG, van Daalen E, van Engeland H, et al. (2006). Identification of novel autism candidate regions through analysis of reported cytogenetic abnormalities associated with autism. Mol. Psychiatry 11: I-18- I-28.

Wassink TH, Piven J, Vieland VJ, Jenkins L, et al. (2005). Evaluation of the chromosome 2q37.3 gene CENTG2 as an autism susceptibility gene. Am. J. Med. Genet. B. Neuropsychiatr. Genet. 136: 36-44.

Wolff DJ, Clifton K, Karr C and Charles J (2002). Pilot assessment of the subtelomeric regions of children with autism: detection of a 2q deletion. Genet. Med. 4: 10-14.

Zafeiriou DI, Ververi A and Vargiami E (2007). Childhood autism and associated comorbidities. Brain Dev. 29: 257-272. 
Anexo C. Artigo submetido ao Journal of Autism and Developmental Disorders em fase de correção solicitada pelo editor.

The $2 q 37$ and $22 q 13.3$ regions in patients with autism spectrum disorders Adriana Barbosa-Gonçalves ${ }^{1}$; Ana Luiza Bossolani- Martins ${ }^{1}$; Cristina B. VendrameGoloni $^{2}$; Camila Ive Ferreira Oliveira ${ }^{1}$; Carina Tatiana Giunco ${ }^{3}$; Simone S. Rocha ${ }^{4}$, and Agnes C. Fett-Conte ${ }^{3}$

1-Institute of Biosciences, Languages and Exact Sciences (IBILCE), Paulista State University (UNESP), São José do Rio Preto, São Paulo, Brazil

2- Base Hospital /FUNFARME, São José do Rio Preto, SP, Brazil

3- Integrated Colleges Padre Albino, Catanduva, SP, Brazil

4- Medicine School in São José do Rio Preto (Famerp), São José do Rio Preto, São

Paulo, Brazil.

\title{
Author Note
}

This work was supported by research grants from the Medicine School in São José do Rio Preto (BAP/FAMERP) and the Brazilian Council for Scientific and Technological Research (CNPq) - Grant numbers: 3317/2004 and 141553/2004-9.

Correspondence concerning this article should be addresses to Agnes Cristina Fett Conte. Hemocentro - Laboratório de Genética. Av. Brigadeiro Faria Lima, $5.544-$ Bairro Universitário. São José do Rio Preto (SP) — CEP 15090-000. Tel. (+55 17) 3201-5000.

E-mail: genetica@famerp.br

\begin{abstract}
Autism spectrum disorders represent a group of neurogenetic conditions that have a wide range of clinical characteristics including altered socialization and communication. Even mild or subtle difficulties can have a profound and devastating impact on the child. Of late, much attention has been given to a marked increase in the reported incidence of these conditions. Considerable debate exists as to the genetic basis of these disorders. Continuing advances in genetic testing provide a moving target for the clinician in determining an appropriated diagnostic plan. Recently, much attention has been paid to the detection of alterations in subtelomeric chromosome regions such as $2 q 37$ and $22 q 13$. In this article we describe the results of evaluations of the $2 q 37$ and 22q13.3 regions in 60 patients with autistic disorders using the fluorescence in situ hybridization (FISH) technique with specific probes. All individuals were also studied using the GTC banding technique to identify possible chromosomal diseases. No alterations were observed, which may be due to the small sample size analyzed but the results suggest that anomalies in these regions, as detected by FISH, are rare in ASD individuals and do not appear to have any potential application in the etiological evaluation of patients.

Key words: Autism spectrum disorders; Chromosome 2; Chromosome 22; Fluorescence in situ hybridization; FISH technique

E-mail: genetica@famerp.br
\end{abstract}




\section{Regions $2 q 37$ and $22 q 13.3$ in patients with autism spectrum disorders}

The DSM IV includes the following autism spectrum disorders (ASD): autistic disorder (AD) (pervasive problems/deficits in all three domains), Asperger's disorder (AS) (pervasive deficits in social interaction and in behavior in the presence of a normal verbal development) and pervasive developmental disorder not otherwise specified (PDD-NOS) (Baumer, 2008; Hofvander, et al., 2009).

There is much difficulty in establishing diagnostic boundaries between diseases considered to be pervasive developmental disorders (Witner, 2008). These are impairing developmental disorders characterized by three core symptom domains: ritualisticrepetitive behavior, impaired social interaction, and impaired communication and language (Rutter, Bailey, Bolton, and Le Couter, 1993). These disorders generally manifest in infancy and are fully present by the age of four (Gilberg, 1993; Wassink, et al., 2007).

Epidemiological studies have described overall prevalence rates for ASD of 57.9-116.1 per 10,000, and rates for autism of 16.8-40.5 per 10,000 (Melville et al, 2008). However, higher frequencies have been proposed. A systematic review of prevalence studies has suggested a figure of 20 per 10.000 for ASD and around 7 per 10.000 for typical autism (Williams, Higgins, and Brayne, 2006). A recent review covering research on these conditions, debates whether the increased prevalence represents better recognition or a true increase (Caronna, Milunsky, and Tager-Flusberq, 2008).

The causes of ASD are still largely unknown. Genetic abnormalities have been a focus of research on the etiology, partly due to the fact that individuals, especially those with autism, in addition to the core symptoms, also experience a variety of physical and behavioral impairments that are commonly associated with chromosomal abnormalities such as mental retardation (Fombonne, 1999; Wassink et. al., 2007), epilepsy (Volkmar and Nelson, 1990; Wassink et. al., 2007), facial dysmorphology (Rodier, Bryson, \& Welch, 1997; Wassink et. al., 2007), and physical anomalies. Additionally, ASD susceptibility has been shown to have a strong genetic component with a sibling relative risk of $\sim 50$ and a heritability of $\sim 90 \%$ (Durand et al., 2006; Persico and Bourgeron, 2006; Wassink et. al., 2007). But, despite the compelling evidence from twin and family studies indicating a strong genetic involvement in the etiology of autism, the unequivocal detection of autism susceptibility genes remains an elusive goal because the molecular basis of most cases remains unexplained (Losh, Sullivan, Trembath, and Piven, 2008).

Linkage and association studies have identified numerous susceptibility genes, mapped on various chromosomes. Many or these genes seem to confer from minor physical malformations to malformations of the central nervous system (Lukusa, Vermeesch, Holvoet, Fryns and Devriendt., 2004; Gupta and State, 2007; Phelan, 2008).

Numerous studies have thus been performed searching for cytogenetic anomalies in individuals with ASD. About $5 \%$ of patients have a chromosome abnormality visible using cytogenetic methods with the most common being the fragile $\mathrm{X}$ anomaly, microdeletions and duplications (Wassink et al., 2007), in particular, 15q11-q13 duplication, and $2 \mathrm{q} 37$ and 22q13.3 deletions (Jacquemont, et al., 2006).

The $2 \mathrm{q} 37$ deletion is a rare condition that results in dysmorphism, occasional major malformations and developmental delay/mental retardation caused by monosomy of 2qter with breakpoint in 2q37 (Phelan et al., 1995; Wilson et al., 1995). Although there is considerable variability in the clinical presentation, neurological abnormalities, 
especially autistic or hyperkinetic behavior, have been described repeatedly. The deleted region in 2q37.3 includes FERM, RhoGEF and pleckstrin domain protein 2 (FARP2), glypican 1 (GPC1), vigilin (HDLBP), kinesin family member 1A (KIF1A) and prolinealanine-rich STE20-related kinase (PASK), all of which are involved in skeletal or neural differentiation processes. It has been hypothesized that haploinsufficiency of these genes may contribute to the patient's clinical phenotype (Felder et al., 2009).

The 22q13.3 microdeletion syndrome is characterized by neonatal hypotonia, overall developmental delay, normal to accelerated growth, absent to severely delayed speech and minor dysmorphic features. Behavior is autistic-like with decreased perception of pain and habitual chewing or mouthing. The true incidence of this syndrome remains unknown. Diagnosis is based on cytogenetic and/or molecular demonstration of loss or disruption of the chromosome 22q13.3 region which contains the SHANK3/ProSAP2 gene (Phelan, 2008).

Detection of these alterations may, apart from contributing to the understanding of biological mechanisms involved in ASD, help genetic counseling of families. The aim of this study was to investigate the subtelomeric region of the long arm of chromosome 2 (2q37) and of the long arm of chromosome 22 (22q13.3) in patients with ASD.

\section{Method Participants}

After approval of the Research Ethics Committee, written informed consent was obtained from 60 individuals with ASD characterized according to the criteria of the DSM-IV. These patients were identified in specialized schools and clinics. Our sample consisted of 46 male and 14 female patients, 25 of whom had been diagnosed with autism, 9 with Asperger's syndrome and 26 with atypical autism (PDD-NOS; nonspecified invasive developmental disorder).

\section{Materials and Procedure}

Sixty patients were tested for the $2 \mathrm{q} 37$ deletion and 53 for the $22 \mathrm{q} 13.3$ deletion. Psychiatrists and psychologists, members of multidisciplinary teams and specialists in ASD made the diagnoses. Patients who presented comorbidities related to genetic syndromes or who had probable environmental factors involved in the etiology of their disease were not enrolled in this study.

Individuals without prior karyotypic investigations were assessed using the GTG banding technique ( 450 bands). Metaphases for the study were obtained from lymphocytes from 5-mL peripheral blood samples cultured for 72 hours according to standard protocols.

Subtelomere FISH studies were performed using Vysis and Cytocell probes for the 2q37 (D2S447) region, for the centromeric region of chromosome 2 (control identification) and for the 22q13.3 region (N85A3). Denaturation of the chromosomes, preparation of the hybridization mixture and post-hybridization amplification were performed according to the manufacturer's guidelines on the use of the probes. All experiments were performed utilizing a slide (of lymphocytes from normal individuals) to control the efficiency of hybridization and two or more slides of each study case.

Analyses were carried out by two researchers who independently analyzed around ten metaphases of each case using an Olympus BX60 fluorescent microscope with filters for DAPI, FITC, rhodamine and a triple filter with an HBO $100 \mathrm{~W}$ light 
source. The criteria for the analysis and description of the results were those reported by Harris et al. (1995) and Eastmond et al. (1995) and contained in the International System for Human Cytogenetic Nomenclature (Schaffer and Tommerup, 2005).

\section{Results}

A normal result for each of the subtelomeric probes was obtained for all 60 patients. All the patients tested for the $2 \mathrm{q} 37$ region by FISH presented with 46,XX.ish $2 \mathrm{q} 37(\mathrm{~N} 8593 \times 2)$ or $46, X Y$.ish $2 \mathrm{q} 37(\mathrm{~N} 8593 \times 2)$. All the patients tested for $22 \mathrm{q} 13.3$ presented with 46,XX.ish 22q13.33(D22575x2) or 46,XY.ish 22q13.33(D22575x2).

\section{Discussion}

The study of subtelomeric areas is becoming of increasing cytological importance since this multifunctional chromosome segment intervenes to keep the number and structure of the chromosomes constant. Screening for submicroscopic chromosome rearrangements in patients with mental retardation but without a recognizable pattern of dysmorphic features has focused on terminal rearrangements. This is because practical tools for whole genome screening are not available and rearrangements that delete or duplicate subtelomeric sequences account for more than $50 \%$ of all cytogenetically detectable chromosomal abnormalities (Slavotinek et al., 1999).

Abnormalities in these regions are thought to be particularly difficult to detect using conventional cytogenetic methods. The ends of most human chromosomes are morphologically similar. High resolution karyotyping (HRK) does not reliably detect abnormalities smaller than $\sim 5 \mathrm{MB}$ in length and can also miss larger abnormalities that do not alter the G-banding pattern (Salman, Jhanwar, \& Ostrer, 2004). Because of this, the FISH technique with specific probes is also used. A probe should produce two signals, one for each autosome, so three or more signals indicate duplication, and less than two indicates deletion (Joyce, Dennis, Cooper, and Browne, 2001; Wassink et al, 2007).

The isolated use of these panels has detected subtelomeric abnormalities in autism (Goizet et al., 2000, Font-Montgomery, Weaver, Walsh, Christensen, and Thurston, 2004;). Two modestly sized studies of autistic individuals, however, were negative. Wolff et al. used subtelomere FISH panels to examine 10 PDD cases, finding one with a 2q37 deletion (Wolff, Clifton, Karr, and Charles, 2002), while for Keller et al., subtelomere FISH found no abnormalities beyond those detected by HRK in an evaluation of 49 PDD individuals (Keller et al, 2003). Recently, our group described a pilot study that investigated the deletion of 2 q37 using the FISH technique in 20 patients with ASD with the results being negative (Barbosa-Gonçalves, VendrameGoloni,, Martins, and Fett-Conte, 2008). In another study (in press), we describe HRK in 15 patients with ASD with only one patient presenting 2 q37 deletion which was not confirmed by the use of FISH (Martins, Barbosa-Gonçalves, Rocha, and Fett-Conte, 2009).

Deletions of chromosome 2 are said to be rare. Most cases are associated with complex duplication-deletion syndromes among progeny of balanced reciprocal translocation carriers. Clinical manifestations vary depending on the location and type of the $2 q$ deletion. Some individuals with autism have been described with alterations at $2 \mathrm{q} 37$, which implicates the $2 \mathrm{q} 37$ as a region of interest for susceptibility to ASD, with possible candidate genes, in particular CENTG2 (centaurin gamma 2 gene) (Vorstman, 
Staal, van Daalen, van England, Hochstenbach, and Franke, 2006; Zafeiriou, Ververi, and Vargiami, 2007). Some patients may have submicroscopic subtelomeric alterations that cause the disorder. But, alterations described at $2 q 37$ are very slight and may be underestimated in the ASD population, as they cannot be detected by cytogenetic analysis using routine GTG banding, to which patients are generally submitted in their clinical genetic evaluation (Riegel and Schinzel, 2002; Sherr et al, 2005).

Although a number of reports of patients with chromosome $2 q 37$ deletion syndrome have been published, it remains unclear if gene expression and/or translation are altered by the deletion and hence whether this contributes to the observed phenotypes. Many other chromosomal imbalances have been described. However, most of them remain undetectable using routine karyotype analysis, thus impeding diagnosis and genetic counseling (Jacquemont, et al., 2006).

Mutations in 22q13 involving SHANK3 have been associated with ASD. This gene regulates the structural organization of dendritic spines and is a binding partner of neuroligins; genes encoding neuroligins are mutated in autism and Asperger's syndrome (Gauthier et al., 2008; Durand et al., 2006).

Alterations in $22 \mathrm{q} 13$, especially the increasing number of $22 \mathrm{q} 13$ deletions that have recently been reported indicate that this type of deletion may be occurring more often than previously thought. According to Luciani et al. (2003) any patient with mild global developmental delay, severe speech delay, and behavioral disorders should be studied using the FISH technique in order to search for a cryptic 22q13 deletion.

Over the last few years, genetic research in ASD has achieved some important advances, including the identification of several vulnerable loci and a few cytogenetic abnormalities or mutations able to cause these disorders. In order to transfer this knowledge into clinical practice, it is critical to define a set of phenotypic inclusion criteria which must be present in affected individuals to justify their inclusion in a specific genetic test. The American Academy of Pediatrics recommends that the primary care provider of a person with autism should initiate the evaluation of the proband by obtaining HRK and fragile X studies (Johnson and Myers, 2007).

We were interested in determining whether subtelomeric investigations using FISH of the 2q37 and 22q13.3 regions would be a useful adjunct screening tool in cases of ASD. Our data, in spite of the modest sample size, suggest that FISH rarely detects anomalies in these regions in ASD individuals with normal karyotypes and thus this does not appear to demonstrate usefulness as a cytogenetic screening tool in this population.

Alternative tools, such as those that are becoming available in the format of micro-arrays, which offer the possibility of improved cytogenetic resolution in large populations of ASD individuals, should be the focus of future effort. However the availability of this technology in the clinical practice will be another question.

\section{References}

Barbosa-Gonçalves, A., Vendrame-Goloni, C. B., Martins, A. L., Fett-Conte, A. C. (2008). Subtelomeric region of chromosome 2 in patients with autism spectrum disorders. Genetics and Molecular Resarch, 7(2): 527-533.

Baumer, J. H. (2008). Autism spectrum disorders, SIGN. Archives of Disease in Chilldhood. Education and Practice, 93(5), 163-166. doi:10.1136/adc.2008.145938.

Caronna, E. B.; Milunsky, J. M.; and Tager-Flusberq, H. (2008). Autism spectrum disorders: clinical and research frontiers. Archives of Disease in Childhood, 93(6), 518523. doi: 10.1136/adc.2006.115337. 
Durand, C. M., Betancur, C., Boeckers, T. M., Bockmann, J., Chaste, P., Fauchereau, F., Nygren, G., Rastam, M., Gillberg, I. C., Anckarsäter, H., Sponheim, E., GoubranBotros, H., Delorme, R., Chabane, N., Mouren-Simeoni, M. C., de Mas, P., Bieth, E., Rogé, B., Héron, D., Burglen, L., Gillberg, C., Leboyer, M., \& Bourgeron, T. (2006). Mutations in the gene encoding the synaptic scaffolding protein SHANK3 are associated with autism spectrum disorders. Nature Genetic, 39(1), 25-27. doi: $10.1038 / n g 1933$.

Eastmond, D., E., Schuler, M., Rupa, D., S. (1995). Advantages and limitations of using fluorescence in situ hybridization for the detection of aneuploidy in interphase human cells. Mutation Research, 348, 153-162.

Felder, B., Radlwimmer, B., Benner, A., Mincheva, A., Grischa Tödt, Beyer, K. S., Schuster, C., Bölte, S., Schmötzer, G., Klauck, S. M., Poustka, F., Lichter, P., \& Poustka, A. (2009). FARP2, HDLBP and PASK are downregulated in a patient with autism and 2q37.3 deletion syndrome. American Journal of Medical Genetics. Part A, 149A(5), 952-959. doi: 10.1002/ajmg.a.32779 .

Fombonne E. (1999). The epidemiology of autism: A review. Psychological Medicine, 29(4), 769-786. doi: 10.1017/S0033291799008508.

Font-Montgomery, E., Weaver, D., D., Walsh, L., Christensen, C., \& Thurston, V. C. (2004). Clinical and cytogenetic manifestations of subtelomeric aberrations: Report of a six cases. Birth Defects Research Part A: Clinical and Molecular Teratology, 70 (6), 408-415. doi: 10.1002/bdra.20036.

Gauthier, J., Spiegelman, D., Piton, A., Lafreniére, R. G., Laurent S., St-Onge, J., Lapointe, L., Ha Mottron, L., Fombonne, E., Joober, R., Marineau, C., Drapeau, P. \& Rouleau, G. A. (2008). Novel de novo SHANK3 mutations in autistic patients. American Journal of Medical Genetics Part B Neuropsychiatric Genetics, 150B(3), 421424. doi: 10.1002/ajmg.b.30822.

Gilberg, C. (1993). Autism and related behaviours. Journal of Intellectual Disability Research, 37(4), 343-372. doi: 10.1111/j.1365-2788.1993.tb00879.x.

Goizet, C., Excoffier, E., Taine, L., Taupic, E., El Moneim, A., Aveiler, B., Bouvard, M., \& Lacombe, M. (2000). Case with autistic syndrome and chromosome 22q13.3 deletion detected by FISH. American Journal of Medical Genetics, 96 (6), 839-844. doi: 10.1002/1096-8628(20001204)96:6<839::AID-AJMG29>3.0.CO;2-R.

Gupta, A. R., and State, M. W. (2007). Recent advances in the genetics of autism. Biological Psychiatry, 61(4), 429-437. doi: 10.1016/j.biopsych.2006.06.020.

Harris, C., Robinson, T., Michalski, K., \& Meisner, et al. (1995). Specimen salvage with FISH. App. Cytogenetics, 21, 66-70.

Hofvander, B., Delorme, R., Chaste, P., Nydén, A., Wentz, E., Stahlberg, O., Herbrecht, E., Stopin, A., Anckarsater, H., Gilberg, C., Rastam M., \& Leboyer, M. (2009). Psychiatric and psychosocial problems in adults with normal-intelligence autism spectrum disorders. BioMed Central Psychiatric, 10, 9-35. doi: 10.1186/1471-244X-935.

Jacquemont, M-L., Sanlaville, D., Redon, R., Raoul, O., Cormier-Daire, V., Lyonnet, S., Amiel, J., Le Merrer, M., Heron, D., Blois, M-C., Prieur, M., Vekemans, M., Carter, N. P., Munnich, A., Colleaux, L., \& Philippe, A. (2006). Array-based comparative genomic hybridization identifies high frequency of cryptic chromosomal rearrangements in patients with syndromic autism spectrum disorders. Journal of Medical Genetics, 43(11), 842-848. doi: 10.1136/jmg.2006.043166.

Johnson, C. P., and Myers, S. M. (2007). Identification and evaluation of children with autism spectrum disorders. Pediatrics, 120(5), 1183-1215. doi: 10.1542/peds.20072361. 
Joyce, C. A., Dennis, N. R., Cooper, S., \& Browne, C. E. (2001). Subtelomeric rearrangements: results from study of selected and unselected probands with idiopathic mental retardation and control individuals by using high-resolution G-banding and FISH. Human Genetics, 109(4), 440-451. doi: 10.1007/s004390100588.

Keller K., Williams, C., Wharton, P., Paulk, M., Bent-Williams, A., Gray, B., Ward, A., Stalker, H., Wallace, M., Carter, R., \& Zori, R. (2003). Routine cytogenetic and FISH studies for $17 \mathrm{p} 11 / 15 \mathrm{q} 11$ duplications and subtelomeric rearrangement studies in children with autism spectrum disorders. American Journal of Medical Genetics A, 117A(2), 105-111. doi: 10.1002/ajmg.a.10042.

Losh, M., Sullivan, P. F., Trembath, D., and Piven, J. (2008). Current developments in the genetics of autism: from phenome to genome. Journal of Neuropathology \& Experimental Neurology, 67(9), 829-837. doi: 10.1097/NEN.0b013e318184482d.

Luciani, J. J., de Mas, P., Depetris, D., Mignon-Ravix, C., Bottani, A., Prieur, M., Jonveaux, P., Philippe, A., Bourrouillou, G., de Martinville, B., Delobel, B., Vallee, L., Croquette, M. F., \& Mattei, M. G. (2003). Telomeric 22q13 deletions resulting from rings, simple deletions, and translocations: cutogenetic, molecular, and clinical analyses of 32 new observations. Journal of Medical Genetics, 40(9), 690-696. doi: 10.1136/jmg.40.9.690.

Lukusa, T., Vermeesch, J. R., Holvoet, M., Fryns, J. P., Devriendt, K. (2004). Deletion 2q37.3 and autism: molecular cytogenetic mapping of the candidate region for autistic disorder. Genetic Counseling, 15(3), 293-301.

Martins, A. L. B., Barbosa-Gonçalves, A., Rocha, S., S., Fett-Conte, A., C.. (2009). Análise Citogenética por Bandamento GTG Convencional e em Alta Resolução da Região 2q37 em Pacientes com Doenças do Espectro Autístico. Revista Arquivos de Ciências da Saúde, 16(3), in press.

Melville, C. A., Cooper, S. A., Morrison, J., Smiley, E., Allan, L., Jackson, A., Finlayson J., \& Mantry D. (2008). The prevalence and incidence of mental ill-health in adults with autism and intellectual disabilities. Journal of Autism and Developmental Disorders, 38(9), 1676-1688. doi: 10.1007/s10803-008-0549-7

Persico, A. M., \& Bourgeron, T. (2006). Searching for ways out of the autism maze: genetic, epigenetic and environmental clues. Trends Neuroscience, 29(7), 349-358. doi:10.1016/j.tins.2006.05.010.

Phelan, M. C. (2008). Deletion 22q13.3 syndrome. Orphanet Journal of Rare Disease, 27, 3-14. doi: 10.1186/1750-1172-3-14.

Phelan, M. C., Rogers, R. C., Clarkson, K. B., Bowyer, F. P., Levine, M. A., Estabrooks, L. L., Severson, M. C., Dobyns, W. B. (1995). Albright hereditary osteodystrophy and $\operatorname{del}(2)(\mathrm{q} 37.3)$ in four unrelated individuals. American Journal of Medical Genetics, 58(1), 1-7.

Riegel, M., \& Schinzel, A. (2002). Duplication of (2)(q11.1-q13.2) in a boy with mental retardation and cleft lip and palate: another clefting gene locus on proximal $2 \mathrm{q}$ ? American Journal of Medical Genetics, 111(1), 76-80. doi: 10.1002/ajmg.10534.

Rodier, P. M.; Bryson, S. E.; \& Welch, J. P. (1997). Minor malformations and physical measurements in autism: data from Nova Scotia. Teratology, 55(5), 319-325. doi: 10.1002/(SICI)1096-9926(199705)55:5<319::AID-TERA4>3.0.CO;2-U.

Rutter, M.; Bailey, A.; Bolton, P.; \& Le Couter, A. (1993). Autism: syndrome definition and possible genetic mechanisms. In S. Baron-Cohen, H. Targer-Flushberg., \& D. Cohen. (Eds.) Nature, nurture, and psychology (pp. 369-284) Washington, DC: APA Books. 
Salman, M., Jhanwar, S. C., \& Ostrer, H. (2004). Will the new cytogenetics replace the old cytogenetics? Clinical Genetics, 66(4), 265-275. doi: 10.1111/j.13990004.2004.00316.x.

Schaffer, L., G., \& Tommerup, N. (2005). An International System for Human Cytogenetic Nomenclature. S. Karger, Basel.

Sherr, E. H., Owen, R., Albertson, D. G., Pinkel, D., Cotter, P. D., Slavotinek, A. M., Hetts, S. W., Jeremy, R. J., Schilmoeller, G., Schilmoeller, K., Wakahiro, M., \& Barkovich, A. J. (2005). Neurology, 65(9), 1496-1498.

Slavotinek, A., Rosenberg, M., Knight, S., Gaunt, L., Fergusson, W., Killoran, C., Clayton-Smith, J., Kingston, H., Campbell, R. H. A., Flint, J., Donnai, D., \& Biesecker, L. (1999). Screening for submicroscopic chromosome rearrangements in children with idiopatic mental retardation using microsatellite markers for the chromosome telomeres. Journal of Medical Genetics, 36(5), 405-411.

Volkmar, F. R.; \& Nelson, D. S. (1990). Seizure disorders in autism. Journal of the American Academy of Child \& Adolecent Psychiatry, 29(1), 127-129.

Vorstman, J. A., Staal, W. G., van Daalen, E., van England, H., Hochstenbach, P. F., \& Franke, L. (2006). Identification of novel autism candidate regions through analysis of reported cytogenetic abnormalities associated with autism. Molecular Psychiatry, 11(1), 18-28. doi: 10.1038/sj.mp.4001757.

Wassink, T. H.; Losh, M.; Piven, J.; Sheffield, V. C.; Ashley, E.; Westin, E. R.; \& Patil, S. R. 2007). Systematic screening for subtelomeric anomalies in a clinical sample of autism. Journal of Autism and Developmental Disorders, 37(4), 703-708. doi:10.1007/s10803-006-0196-9.

Williams J. G.; Higgins, J. P. T.; and Brayne, C. E. G. (2006). Systematic review of prevalence studies of autism spectrum disorders. Archives of Disease in Childhood, 91(1), 8-15. doi: 10.1136/adc.2004.062083.

Wilson, L. C., Leverton, K., Oude-Luttikhuis, M. E., Oley, C. A., Flint, J., Wolstenholme, J., Duckett, D. P., Barrow, M. A., Leonard, J. V., Read, A. P., Trembath, R.C. (1995). Brachydactyly and mental retardation: an Albright hereditary osteodystrophy-like syndrome localized to 2q37. American Journal of Human Genetics, 56(2), 400-407.

Wolff, D. J., Clifton, K., Karr, C., \& Charles, J. (2002). Pilot assessment of the subtelomeric regions of children with autism: detection of a $2 \mathrm{q}$ deletion. Genetics in Medicine, 4(1), 10-14. doi:

Zafeiriou, D. I., Ververi, A., \& Vargiami, E. (2007). Childhood autism and associated comorbidities. Brain and Development, 29(5), 257-272. doi: doi:10.1016/j.braindev.2006.09.003. 